\title{
CONSTRUCTING AND WORKING \\ . THE BOWSHAPED CONCRETE BENCH
}

3 ACKU 000057819

\author{
- A WORK MANUAL FOR \\ CONCRETE BENCH GARDENING
}

\section{By Eva Winberg}

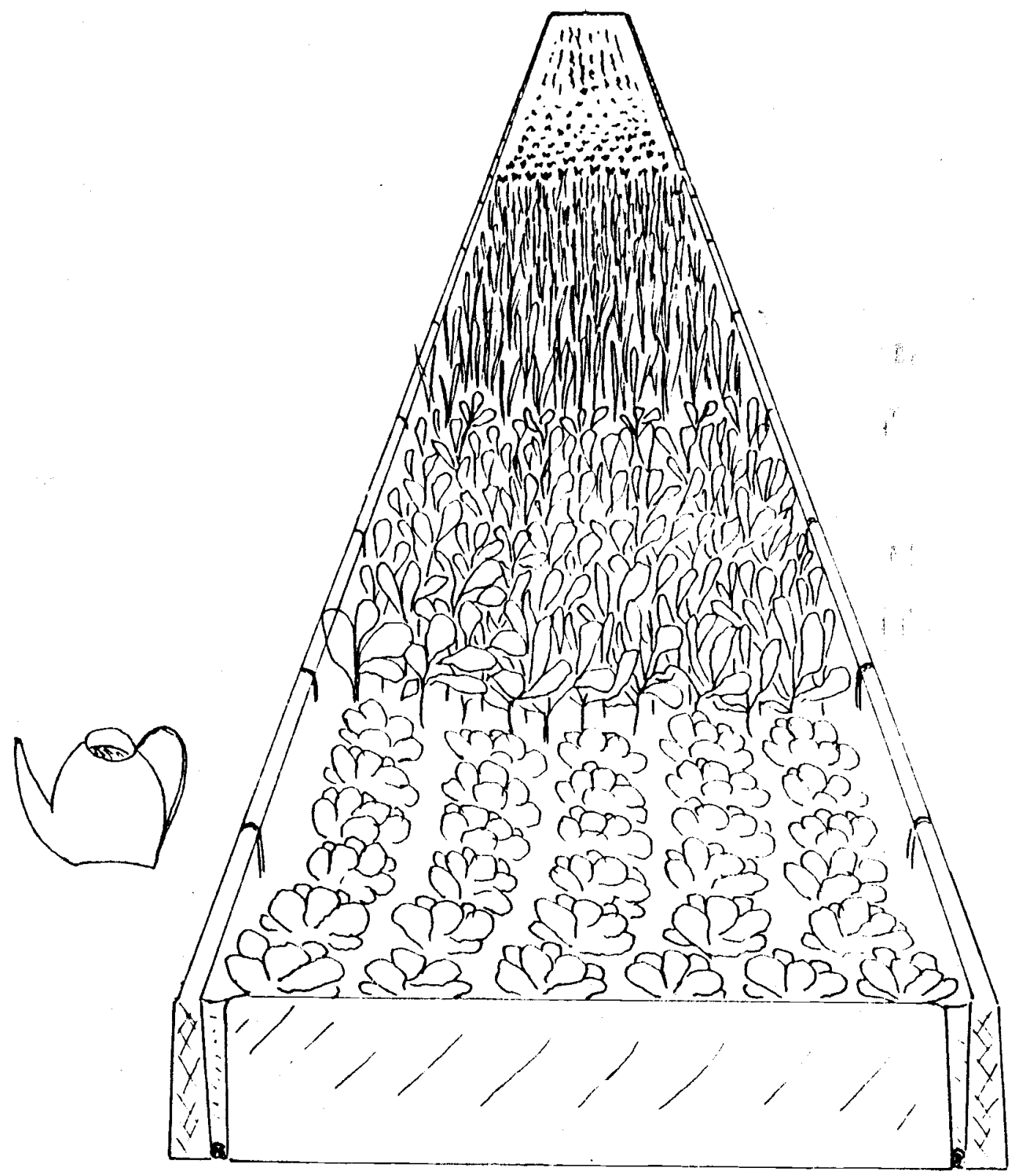


Introduction - : 1

Construction 3

Choosing the growing plot 3

Preparing the ground and narking 3

Filling in of space between slabs for drainage space 7

Filling of concrete bench $\quad 8$

$\begin{array}{lll}3.1 & \text { Initial fertilizing on bottom } & 9 \\ 3.2 & \text { Growing media: sand (soil) } & 9\end{array}$

3.3 Topdressing 10

4 Futher fertilizing 10

4.1 Fertilizing before each planting 10

4.2 Fertilizing during growing period 10

5 Cultivating in concrete benches 11

$5.3 \quad$ Sowing in seed bed $\quad 11$

$5.4 \quad$ Planting of seedlings in concrete bench 12

6 Inigation 14

6.1 Dripwater irrigation 14

6.2 Hand irrigation 1.5

7. Pests and other poblems 16

$\begin{array}{lll}7.1 & \text { Pest control without pesticides; suggestions } & 17\end{array}$

$\begin{array}{lll}7.2 & \text { Pest control with pesticides } & 18\end{array}$

$7.3 \quad$ Frost and hailstorm $\quad 19$

8 The bowshaped conciete bench gauden; an example 20

How to mix concrete 21

Concrete mixes $\quad 22$

How to form concrete slabs $\quad 23$

$\begin{array}{ll}\text { Sowing in seed tray } & 25\end{array}$

Replanting of seedlings into individual trays 26

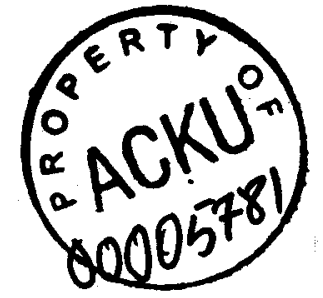


The concrete bench horticultural technique was introduced in Botswana by Dr Gösta Nilsson. He has been living and working in Botswana since 1967, outside Gaborone. Dr Gösta Nilsson has refined the technique further at his fanily enterprise Sanitas Nurseries \& Garden Centre. He has constructed a bowshaped concrete bottom to avoid waterlogging which can harm plant roots in bottom of benches.

The bowshaped concrete bench described in this manual (see drawing below) consists of a frame consisting of one meter long concrete slabs. In between the slabs are drainage holes for excess water. The bowshaped (convex shaped) bottom is coated with a layer of concrete. The belich is filled with fine soil or sand. The benches in this manual measure $20 \mathrm{~m} \times 1.2 \mathrm{~m}$ (191/2 slabs on each long side and 1 slab on the short sides). Constructionmaterials and other materials are adjusted to this size of bench. A wider bench than $1.2 \mathrm{~m}$ may be difficult to manage.

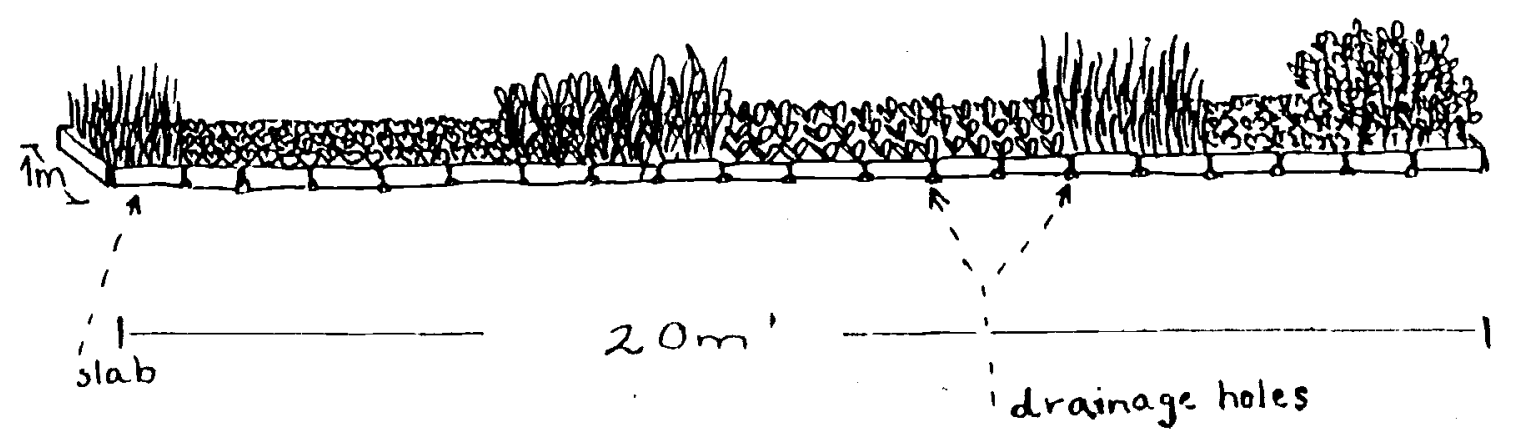

Fig. 2.1 The bowshaped concrete bench showing size, slabs and drainage loles

The bowshaped concrete bench horticultural technique is an irrigation technique. It needs a constant supply of water. Daily watering is required, especially in sümer. Handwatering and drip water irrigation are examples of irrigation methods used. The teclinique requires only 50-70\% water, according to Dr. Gösta Nilsson, compared with conventional growing methods. The bench technique can be used for all kinds of vegetables and there is no need for pesticides.

There is no need to have a fertile soil. The growing media is filled into the benches. Any soil can be used as growing media. To use sand in the benches gives several advantages especially for a country like Botswana. It is, among other things:

- easily accessible

- easy to manage; the sand can be worked with a hand-rake only and replanting can be done immediately after harvest.

The initial cost of construction materials etc. may seem high. Howeler, a properly managed bench can, already after the first year in production, produce a yield that well covers the initial costs. 
The technique referred to in this manual has been studied at Sanitas with Dr. Gösta Nilsson as a mentor. He has been using the technique successfully since his introduction of the technique in the country. He has also further developed not only the technique itself but

- also several solutions making both construction and cultivation easier (tools for example). Furthermore, he is one of the few horticulturalists in Botswana who uses inexpensive, alternative, measures for control of pests. This manual is mainly based on his knowledge and experiences. Dr. Gösta Nilsson runs a medium sized enterprise with about 80 employees. When choosing this technique for smaller schemes such as school vegetable gardens there could be alternative methods both in terms of construction and cultivating that could be considered depending on the local conditions. Some alternatives are mentioned in this manual.

This work manual ains to function as basic information material and to give an understanding of how to construct and cultivate in bowshaped concrete benches. The manual is, above all, intended for individuals and groups with a basic knowledge in horticulture who are interested in knowing more about the technique and maybe starting up their own cultivating scheme. It is not meant to be a general gardening handbook. It does not cover the cultivating in the benches. There is excellent literature and information available in this field. It does, though, give some advice on how to deal with different problenis that may occur during cultivating in concrete bencles. Many of these solutions have been developed and tried out by Dr Gösta Nilsson at Sanitas Nurseries \& Garden Centre. 


\section{Construction}

An appropriate division of labour for the construction of a bowshaped concrete bench is 2 5 persons, depending on what part of the construction is being made.

\subsection{Choosing the growing plot}

The cultivation area should be nat, although a slightly sloping ground is also acceptable. On a slope with a gradient it is possible to construct the concrete benches along the contours. It is important to get an even distribution of the irrigation water, not in any one direction. If there is excess water it should flow out of the drainage holes on the sides of the bench.

\subsection{Preparing the ground and marking}

Suggested tools: meter-long iron rods, strong twine, hricks (or big stones), hoe, spade, wheelbarrow, measuring tape

- Clear the surface of bushes and stones.

- Measure the ground for the sides of the concrete bench using the iron rods and the twine. Bricks or stones can be put on top of the twine to hold it in place.

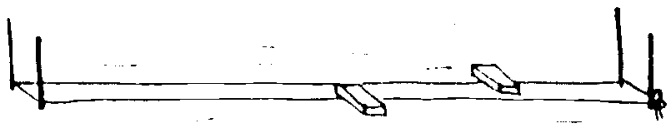

Fig. 2.2 Measuring for the limrows

fig.2.3 Making a shallow firrow akong the marking and letting water run through to sofien the sides

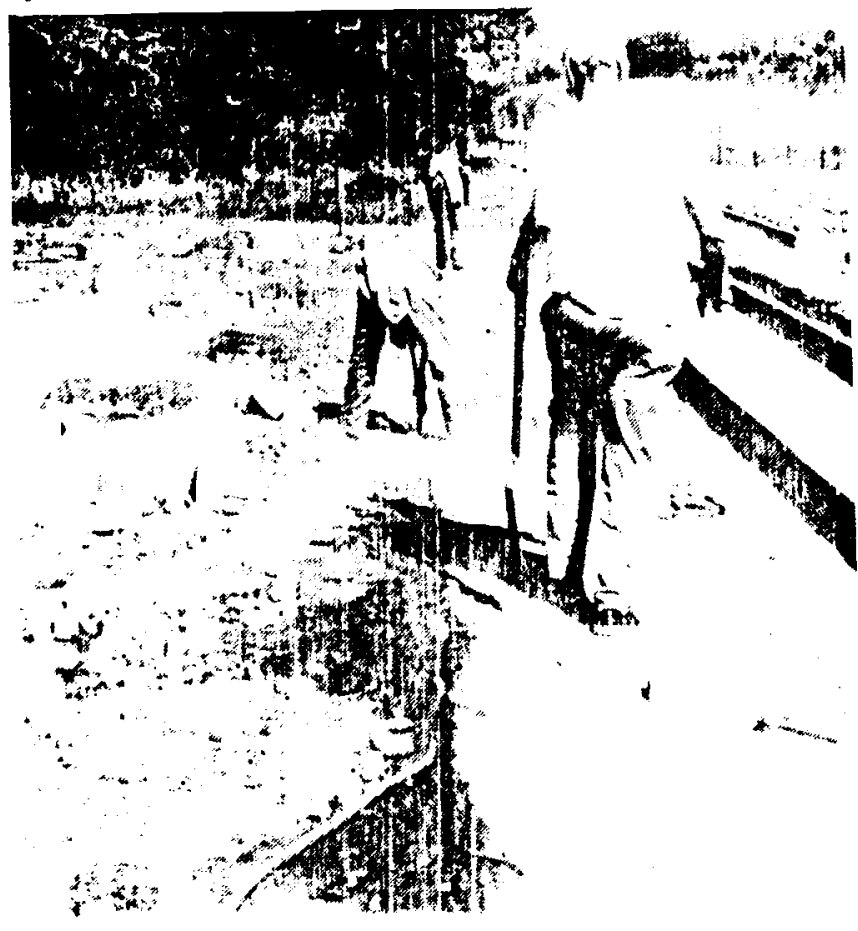

- Make a rough marking on the ground for the sides of the concrete bench along the line

- Push up the cord to about $15 \mathrm{~cm}$ above ground.

- Make a shallow furrow along the marking. Let water run through the furow to soften the sides. Level the sides and dig a little if needed. When ready, the furrows should be about $12 \mathrm{~cm}$ wide and $10 \mathrm{~cm}$ deep. Loose soil, plus extra soil fron the side. should be shoveled to the ground between the funows. It will later be used to shape the bow shaped bottom. While this is done the concrete for the furrows can be prepared. 


\subsection{Placing of concrete slabs in furrows (long sides)}

Suggested tools: level, wheelbarrow, trowel, stick or a piece of a garden hose $(1.5 \mathrm{~cm}$ in diameter), hoe, spade, measuring tape

Information on how to mix concrete; see appendix...

Information on concrete nixes; see appendix...- Iiumbus

Information on how to make concrete slabs; see appendix...-Slahs.

- Mix the concrete for the furrows.

- Fill the first meter in one of the two long furrows with concrete

- Fit in one concrete slab (no. 1) into the furrow filled with concrete. The bottom of the slab should be level with the ground. The slab should only be pressed down a little bit into the furrow. It is important that the slab is standing straight in the furrow. The other slabs will fit in according to this first one. Use a level and the livine to get a good fit. The twine should now be tightly stretched along the upper edge of the slab, $10-12 \mathrm{~cm}$ above ground. Form the excess concrete on both sides of slab smoothly in a concave fashion to meet the ground using the trowel. Add extra concrete if necessary.

liz. 2.4 Placing of slab number $I$ in the furrow

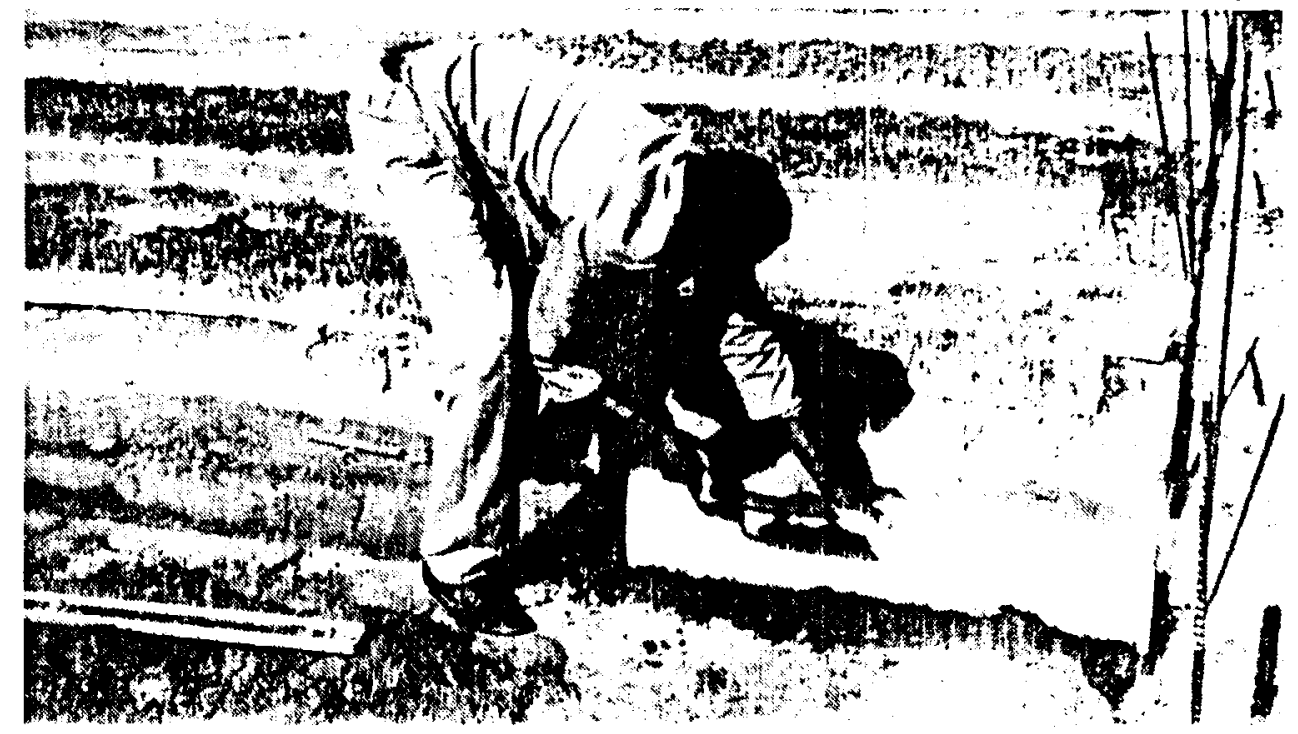

- Fit in a slab into the other end of the furrow (slab no. 20) in the same way as with the first one (no. 1) using the level and the twine.

- Fill in concrete and fit in slabs (no. 2-18) using the twine as a guide ohsenc: there must be a space of $1.5 \mathrm{~cm}$ between each slab for the drainage of excess water. Use, for example, a piece of a garden hose or a stick to $g^{n t}$ the space in between the slabs.

- Slab no. 19 must be divided. 'The sharp edge of the hoe and a stone could be used to divide the slab. Fit it in between slab no. 18 and slab no. 20 with drainage space on both sides.

Fig. 2.5 Drainage space with piece of garden hose

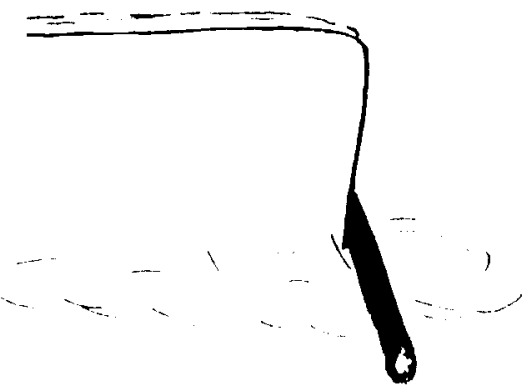


1. 2.2.6 The first row is ready

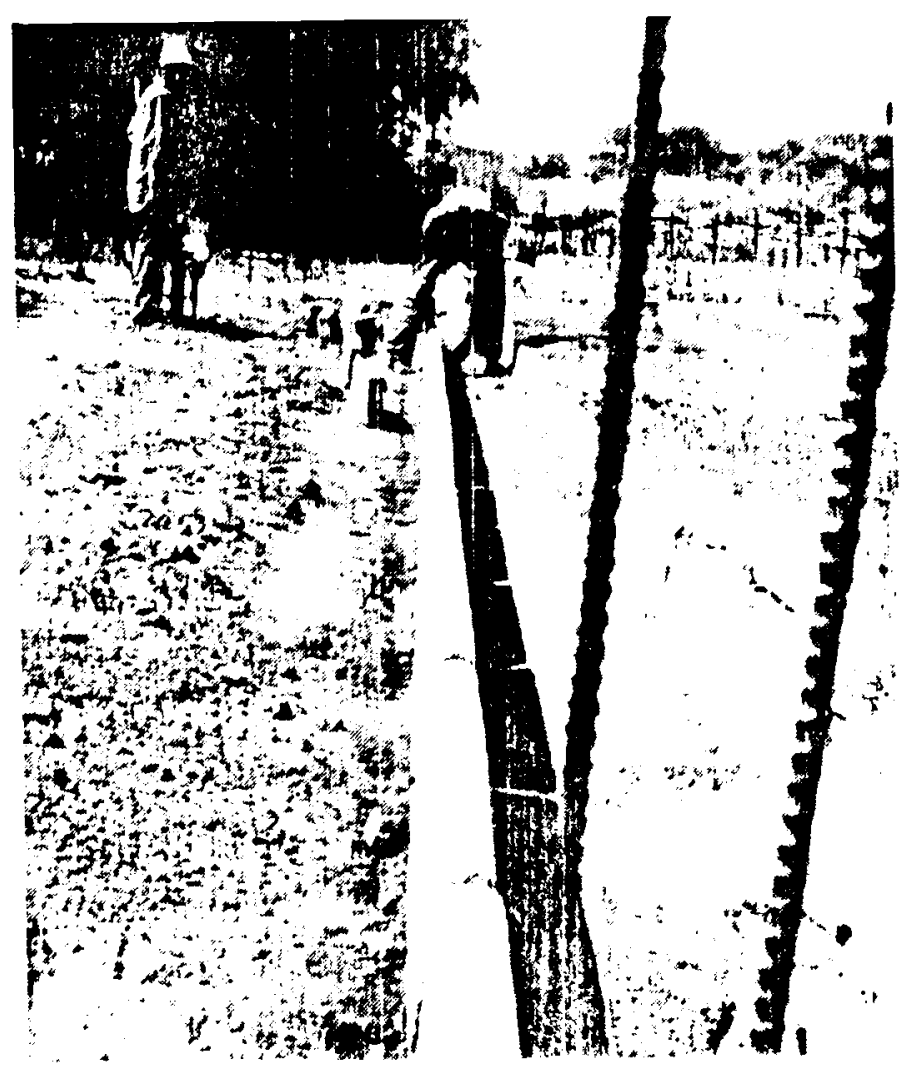

- Fit in the slabs in the other long furrow in the same way as with the first furrow (slab no. 1 and slab no. 20 with good fit, slab no. 2-19 with the twine as a guide). Now the two long sides of the concrete bench are ready.

- If there is concrete left it can be used later for the short sides. Put a plastic sheet over it to keep moist.

\subsection{Shaping and plastering of concrete bottom}

Suggested tools: rake, levelling board, stamp, spade, wheclbarrow

Information on how to mix concrete; see appendix...

Information on concrete mixes; see appendix.... Concretc borrom

Fig. 2.7 The bowshape bench bottom

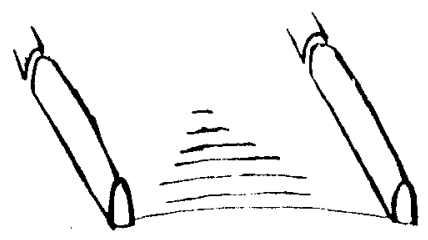

- Build up the ground between the concrete sides with the help of the shoveled earth to form a slightly convex shape, high in the middle, around $2 \mathrm{~cm}$, and sloping on all four sides. This form helps to guide the excess water out through the drainage holes (see drawing). It is important not to make the "hump" too big. It could result in the drying out of plants in the middle of the bench due to lack of water. Use a rake and a levelling board. Water the ground slightly and stamp hard with the stamp. 

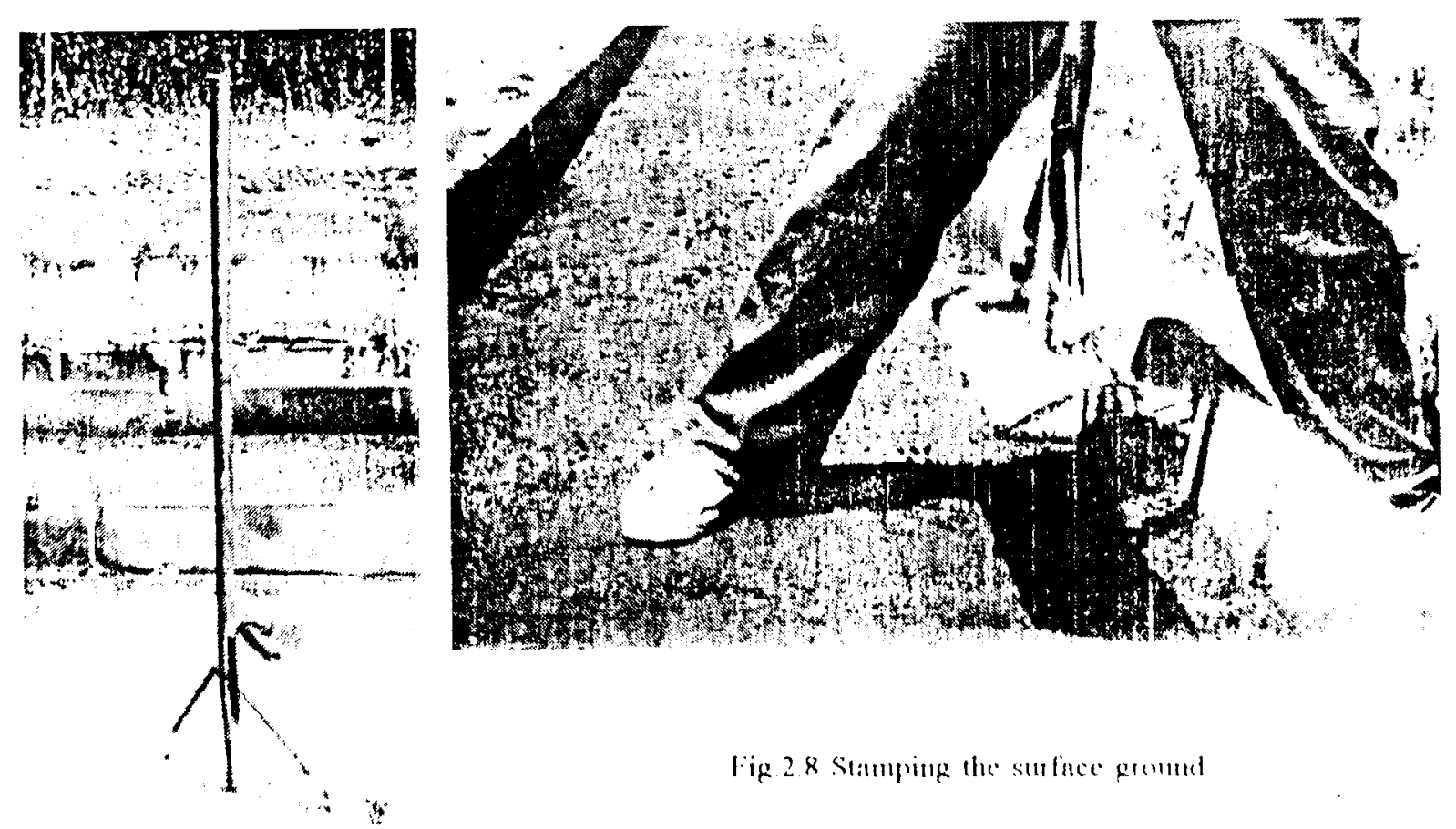

fig 28 Stamping the sufiace gromms

lig 29 The stamp

- Mix the concrete for the bottom.

- Fill the wheelbarrow with concrete and shovel it out evenly with the spade and a rake on the bowshaped bottom. Proportions: one wheelbarrow cement per 1!: running meter makes approx. $25 \mathrm{~mm}$ thick concrete bottom. Clear the concrete of larger stones and even out the concrete with the levelling board

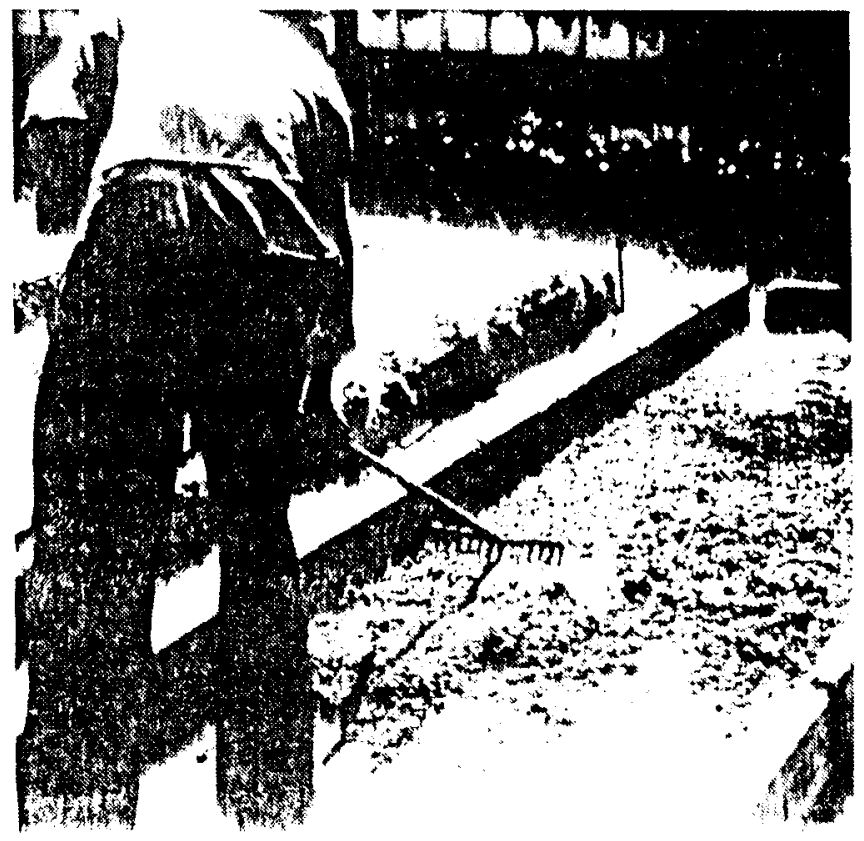

Lip 2.10 Shoveling out of concrete on to the suf face

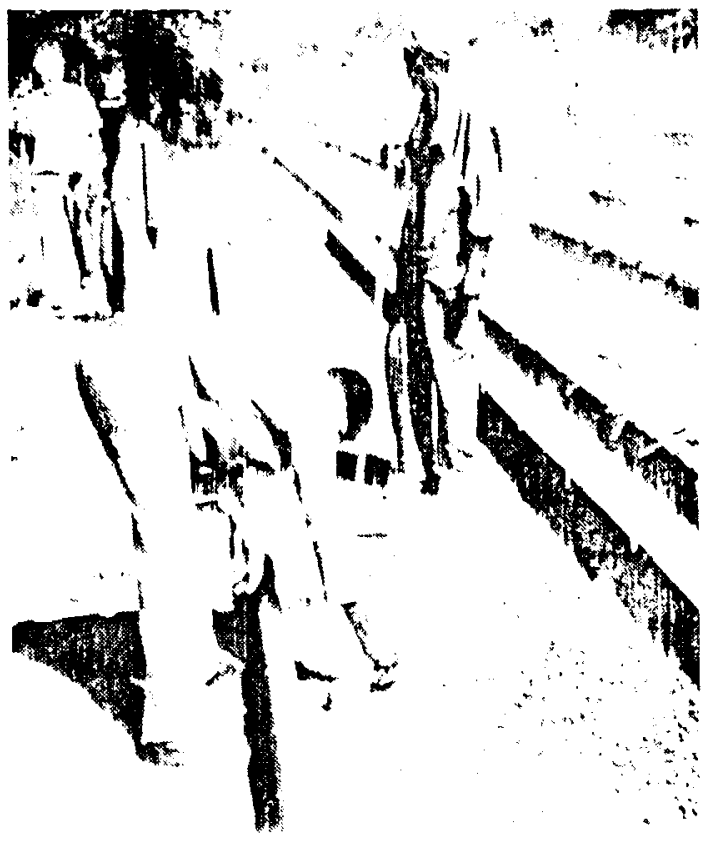

Fig. 211 lisening wht the cencrete: with a lecelling hond 
Suggested tools: same as above

- Fill in concrete and fit in the slabs in the furrows on the short sides. Don t forget drainage space. If there is concrete teft from the fitting in of the long side slabs it can be used. Otherwise it is necessary 10 make a new small mix (Information on concrete mixes; see appendix -furmws) which can also be used to fill the gaps between slabs.

\subsection{Filling in the space between slabs for drainage}

Suggested tools: trowel, piece of garden hose or similar, stick, levelling board, stone, wheelbarrow, spade, brush

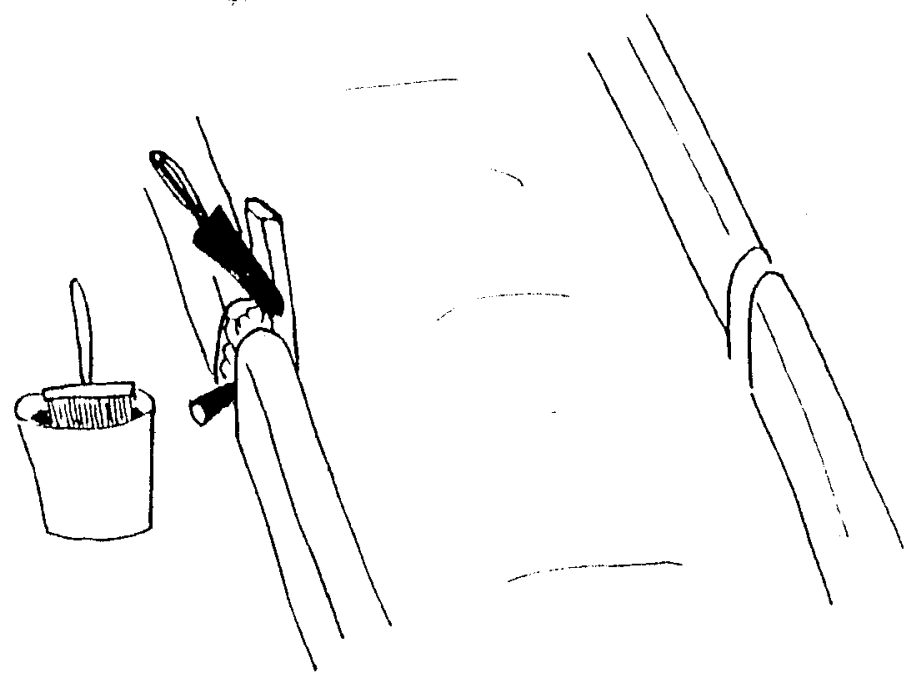

Fig.2.12 filling in the space between slabs with concrete

- ('lear the gap between the slabs with a stick, etc.. For the excess water to drain away easily, make sure the bottom of the gap slopes outwards

- Wet the concrete on both sides of the gap with the brush

- Put the piece of garden hose or stick in the bottom of the gap to keep the drainage hole open. Fill in the upper part of the gap with concrete using a trowel. Ind the levelling board or a piece of plank on the opposite side for support.

- Smooth the concrete out.

- Pull out the hose or stick and move it to the next gap. Repeat the procedure until all the drainage holes are made. If the gap is too big, use any suitable pieces of cut off slats, etc to fill the gap.

- When the concrete in the gaps has dried the edges can be smoothed with a stone etc. Sprinkle the whole bench with water. 


\subsection{Skimming of concrete bottom}

To skim the concrete bottom with a mixture of very fine soil and cement raises the water resistance capacity by filling in the pores in the concrete bottom.

Suggested tools: broom, wheelbarrow, spade, a long brush, stick

Information on how to mix concrete; see appendix Information on concrete mixes; see appendix...-Skimming

- Sweep the bench clear from loose concrete etc.

- Collect the fine soil, for example from underneath a termite mound.

- Mix the soil with cement and water.

- Water the bench.

- Fill the wheelbarrow with the gruel-like mixture and pour it out over the concrete bottom a little at a time. Spread it out evenly with sweeping movements using a short bristled brush. Stir the mixture in the wheelbarrow constantly to make an even mixture.

- Let the bottom dry first. Then water it a couple of times to make the bottom hard and water resistant.

\section{Filling of concete bench}

Now the concrete bench is ready to be filled with sand or finer soil. To grow vegetables in sand works excellently. The sand grains are relatively large as they can be seen with the naked eye. There is a lot of space between them for water to seep through. When watered. water seeps easily down through the sand to the plant roots. Sand is easy to manage. There is no need for plowing etc. With a rake the sand can easily be worked manually. The few sand weeds, if any, are easily uprooted by hand.

In finer soil, the small grains are so tightly pressed to one another that it is more difficult for the water to find its way down to the roots. Often, only the upper layer of the soil gets wet. Then there is a risk that the moisture evaporates before it can give nourishment to the plants. If overwatered there is a risk of a thin, crustlike, surface layer becoming formed which totally prevents the water from seeping down. In Botswana, sand is mostly easily accessible. To fill the benches, any sand is suitable. In other countries, it may be easier and better to use finer soil. In this manual, sand is chosen as a growing nedia. 
For a successful harvest it is important to fertilize. When growing vegetables in the same area year after year additional fertilizing is also necessary to maintain the nutrient quality in the soil.

Original fertilizing suggestion for one bench:

10 buckets of kraal manure (alternatively 7.5 buckets of chicken manure)

$500 \mathrm{~g}$ of superphosphate

$250 \mathrm{~g}$ of $2: 3: 0$ and

$250 \mathrm{~g}$ of $2: 3: 2$ mixed together

Note: if clicken manure from chicken farms is used and the chickens have received a balanced diet there is no real need for superphosphate, $2: 3: 0$ or $2: 3: 2$. The manure and the other fertilizers are spread out evenly over the bench bottom. If an even spread is not achieved the plants will grow unevenly.

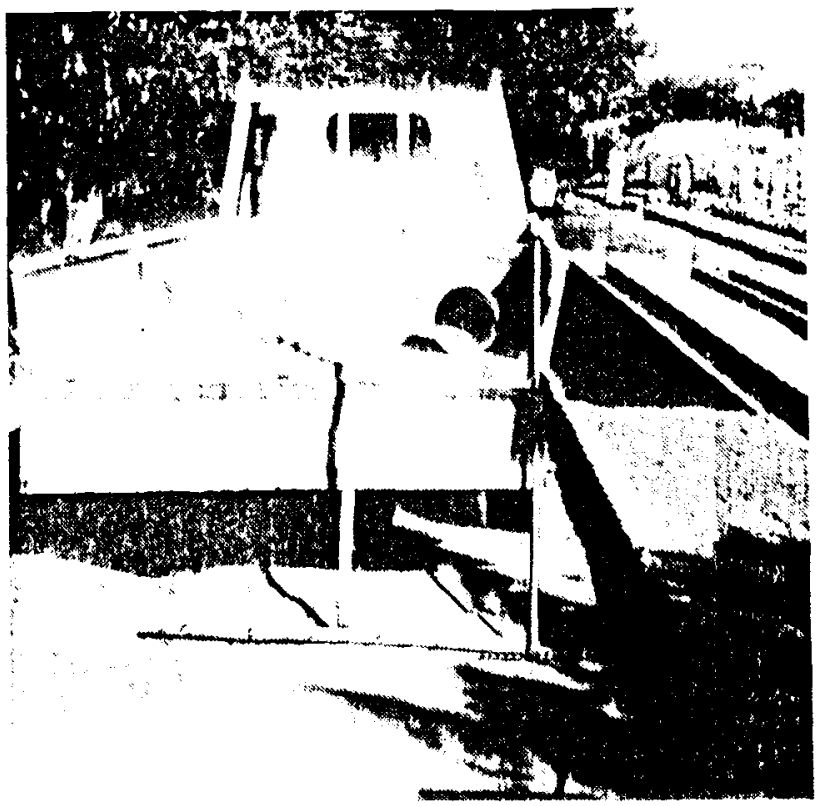

Fig. 2.13 lilling in the sand in the bench

Fig. 2.14 Fentilizing on the botton

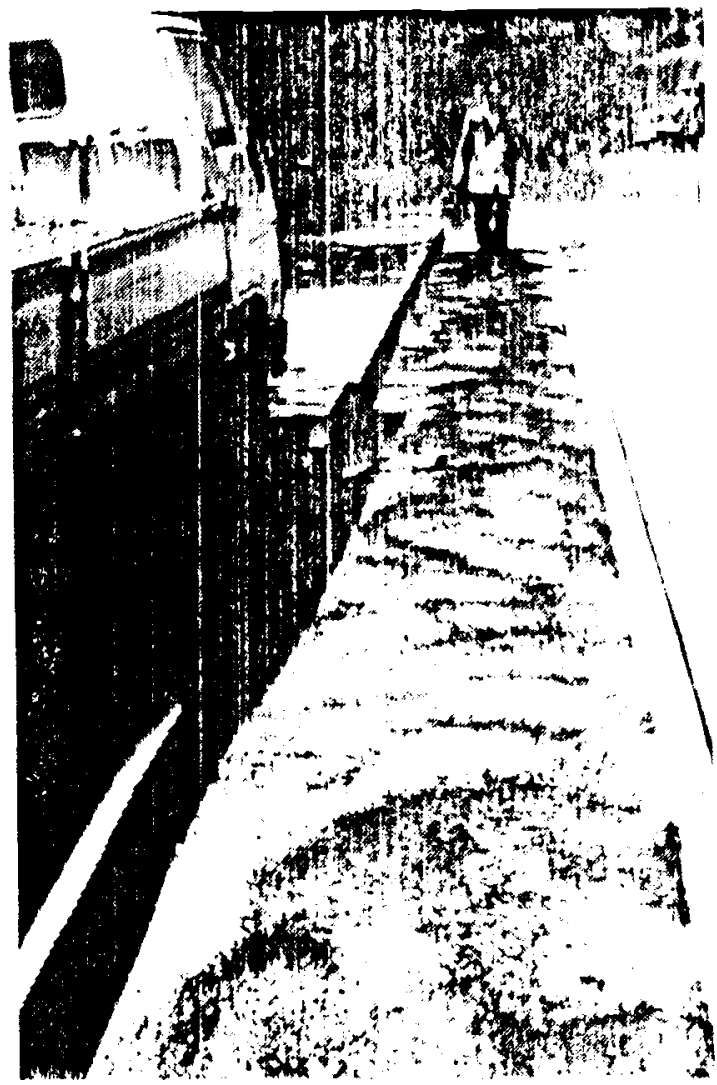

3.2 Growing media - sand

Suggested tools: Spade, rake

- Shovel the sand into the bencli and spread evenly all the way up to the edge. As the sides of the bench are $20 \mathrm{~cm}$ high and the inner measurements are $1.2 \mathrm{~m} \times 20 \mathrm{~m}$ it takes $0.2 \mathrm{~m} \times 1.2 \mathrm{~m} \times 20 \mathrm{~m}=4.8 \mathrm{cu} \mathrm{m}$ sand to fill a bench. $A$ medium-sized Inry can take $5.5 \mathrm{cu} \mathrm{m}$ 


\subsection{Topdressing}

To get a good mineral balance in the sand it is recommended to add an organic fertilizer. There are different organic fertilizers on the market. One is: "Nature s own lawn and garden", an organic fertilizer and soil conditioner. It contains several different minerals and other nutrients that are lacking in the sand. Recommended quantity is 12.5 liters (less than $11 / 2$ bucket) per bencli. An alternative topdressing is dry chicken manure. Recommended quantity:

$1-2$ liters/sq $m=12-24$ liters/ bench

Suggested tools: bucket(10 litre), rake

- Spread evenly and rake slightly into the sand

\section{Funther fentilizing}

\subsection{Fertililizing before each planting}

Suggested tools: bucket( 10 litre)

After each harvest, before replanting, apply new nourishment in the form of kraal manure or chicken manure and mineral fertilizers on top of the sand.

Apply evenly in each bench:

20 liters ( 2 buckets) of $\mathrm{kraal}$ - or chicken manure ( 0.8 liters $/ \mathrm{sq} \mathrm{m}$ )

$250 \mathrm{~g}$ of $2: 3: 2(10 \mathrm{~g} / \mathrm{sq} \mathrm{m})$

$250 \mathrm{~g}$ of Superphosphate $(10 \mathrm{~g} / \mathrm{sq} \mathrm{m})$

( $50 \mathrm{~g}$ of trace elements $(2 \mathrm{~g} / \mathrm{sq} \mathrm{m})$ )- not necessary

\subsection{Fertilizing during growing period}

When growing leafy vegetables it is important to topdress with LAN (Lime Ammonium Nitrate) once every two weeks starting two weeks, after planting. Note: Carrots do not need $L \wedge N$.

Apply evenly in each bench:

$125 \mathrm{~g}$ of LAN

( $100 \mathrm{~g} /$ cubic metre water of potassium nitrate)- not necessary 


\section{Cultivating in concrete benches}

The actual growing of plants in concrete benches (including cultivation of seedlings) does not differ significantly from any other horticultural technique. The controlled fertilizing and irrigation within the confined space makes it possible to plant the vegetables close to one another. The only limitation is the expected size of the vegetable.

Some plants may well be sown directly in the benches for example: beans, peas, onion and carrots. Thin out in the rows when the plants are $10.15 \mathrm{~cm}$ high. Other vegetables such as tomatoes, sallad, spinach, cauliflower, chomolier and cabbage should first be sown in a nursery or a seedbed to get planted at a later stage. Roughly $5 \%(1 / 20)$ of the whole cultivation area will be needed for a seedbed or a nursery. One bench or part of a bench can be used as a seedbed.

Whether sowing directly in the benches or planting at a later stage, the only preparation needed is a light raking of the sand surface and a thorough watering of the bed. Then all that is needed is to make a hole for the seed or the plant, to cover the seed or plant roots. and press lightly. To assure a good economy it is always useful to have seedlings ready for replanting into the benches once the previous harvest is done. This needs good planning

\subsection{Sowing in seedbed}

If there is also a nursery at the same place as the plantation, sowing and cultivating of seedlings can be done there; see appendix-Sowing in seedtray and -Replanting of seedlings into individual trays. But if no nursery is available, one part of the cultivation area $(1 / 20)$ can be used as a seedbed.

To avoid - or get rid of - nematodes or other soil pests it is wise to change the sand in the seedbed before every sowing of seeds. As an alternative, the sand in the seedbed can be treated with very hot water to kill off the nematodes (see chapter 7.1: Pest control without pesticides). Try to use treated seed as much as possible

- Water the seedbed thoroughly.

- Make a shallow furrow for the seeds.

- Sow the seeds in the furrow and cover with $1-2 \mathrm{~cm}$ of salid.

- Water the seedbed. Water twice a day, otherwise the seeds will die.

- When the seedlings are $10-15 \mathrm{~cm}$ high they can be planted into respective bench. 
Suggested tools: Hoe, rake, nuarker

- Water the bench.

- Clear the sand from weeds.

- Hoe the surface lightly if the sand surface is hard.

- Rake the surlace even.

At Sanitas, a simple wooden construction, a" marker", is used to get an even spacing between plants, according to their needs, when planting. The "marker" is pulled through the sand both along the full length of the bench and across it from side to side. The nails attached to the "marker" make fine furrows that can be used as guide lines for even crop spacing.
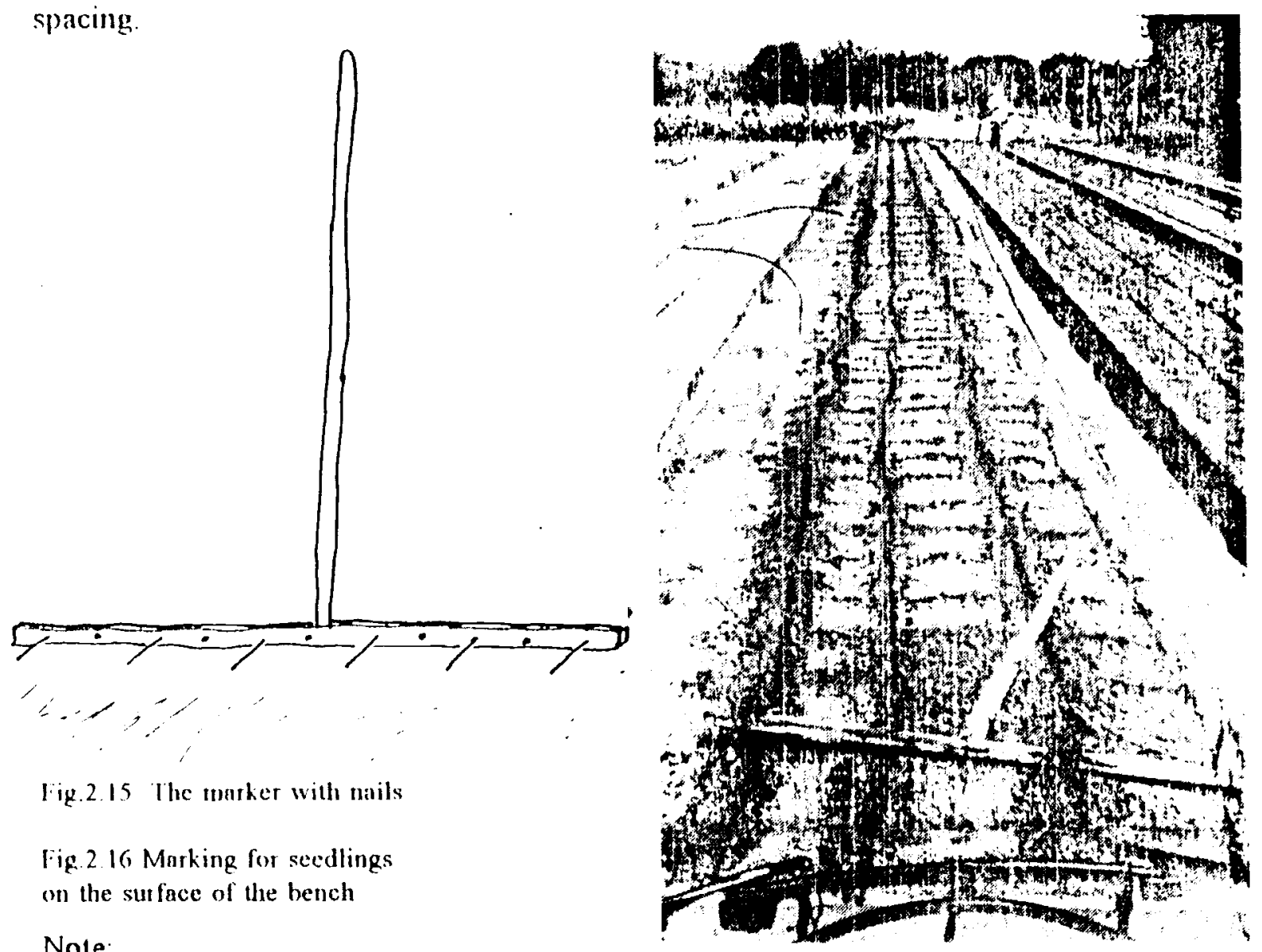

lig.2.15 The matker with nails

Fig. 2.16 Marking for seedlings on the sutface of the bench

\section{Note}

- If planting has been done previously, fertilize according to instructions: see page 4.I Fertilizing before each planting. If the bench has never been used hefore fertilizing and lopdressing have already been done according to instructions: see page.

3.1 Original fertilizing of bottom and 3.3 Topdressing.

- Depending on the needs of the different vegetable types, Inark for rows and plant space.

- Make a hole at every cross made by the marker and plant a seedling in the hole. Press the sand lightly around the seedling.

- Water the bench.

- After 6-7 weeks, depending on type of vegetable, the plants are ready for harvest Replanting can be done immediately after harvest. 


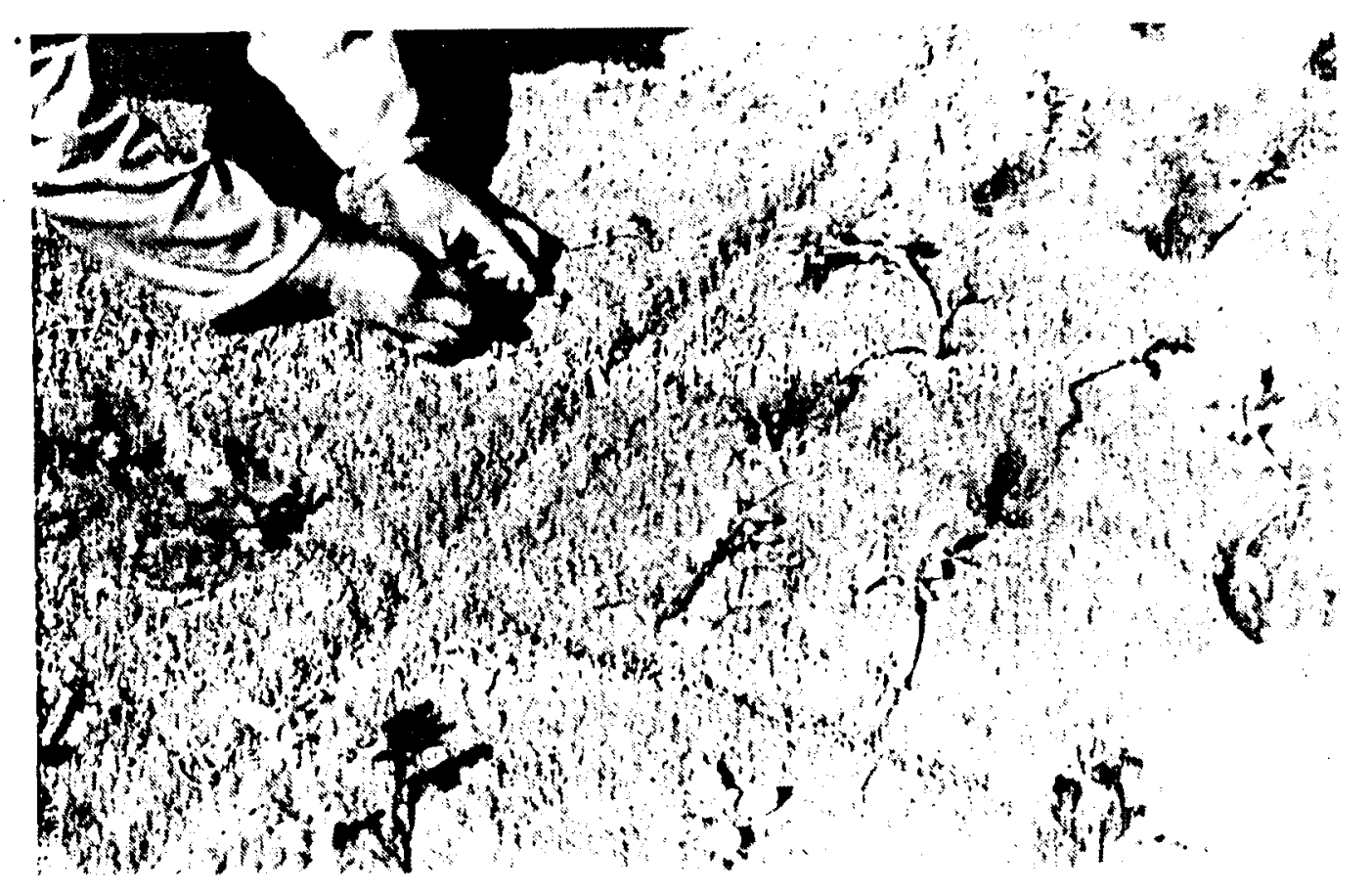

lig. 2.17 Planting of scedlings

Fig. 2.18 the seedling trolley

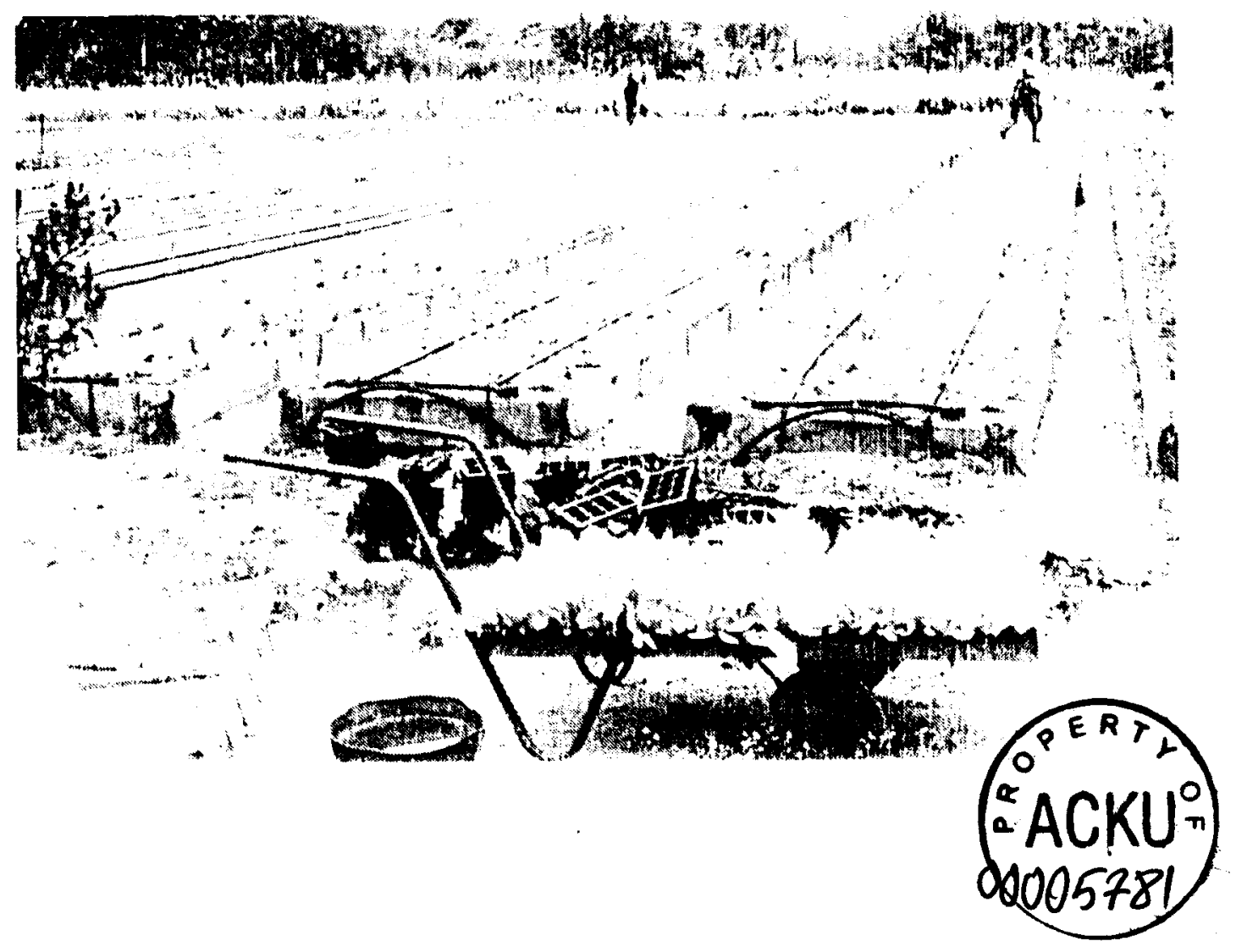




\section{Inigation}

This horticultural technique can be called a watersaving technique. When cultivating in the bowshaped concrete benches, only $50-70 \%$ of the daily water is needed, compared with the intensive irrigated cultivating in open ground. Despite this fact, one must add that concrete bench gardening is a technique that demands a constant and reliable water supply. Therefore, rainwater harvesting, or using temporary surface water, especially in a dry country like Botswana with a low, irregular, unreliable yearly precipitation and a high evaporation, can only be considered as a complement to a continuous water supply from a municipal watersystem or a well. Furthermore, according to John Gould at Dept. of Envirommental Science, University of Botswana, the rainwater collecting surfaces and storage tanks would have to be very big and construction of them would be very expensive.

To irrigate concrete benches, $1-1.2 \mathrm{cu} \mathrm{m}$ of water/ $\mathrm{sq} \mathrm{m}$ is needed per year and about 3 liters/sq $\mathrm{m}$ is needed per day. For one concrete bench, this means $25 \mathrm{cu} \mathrm{m}$ of water/ year

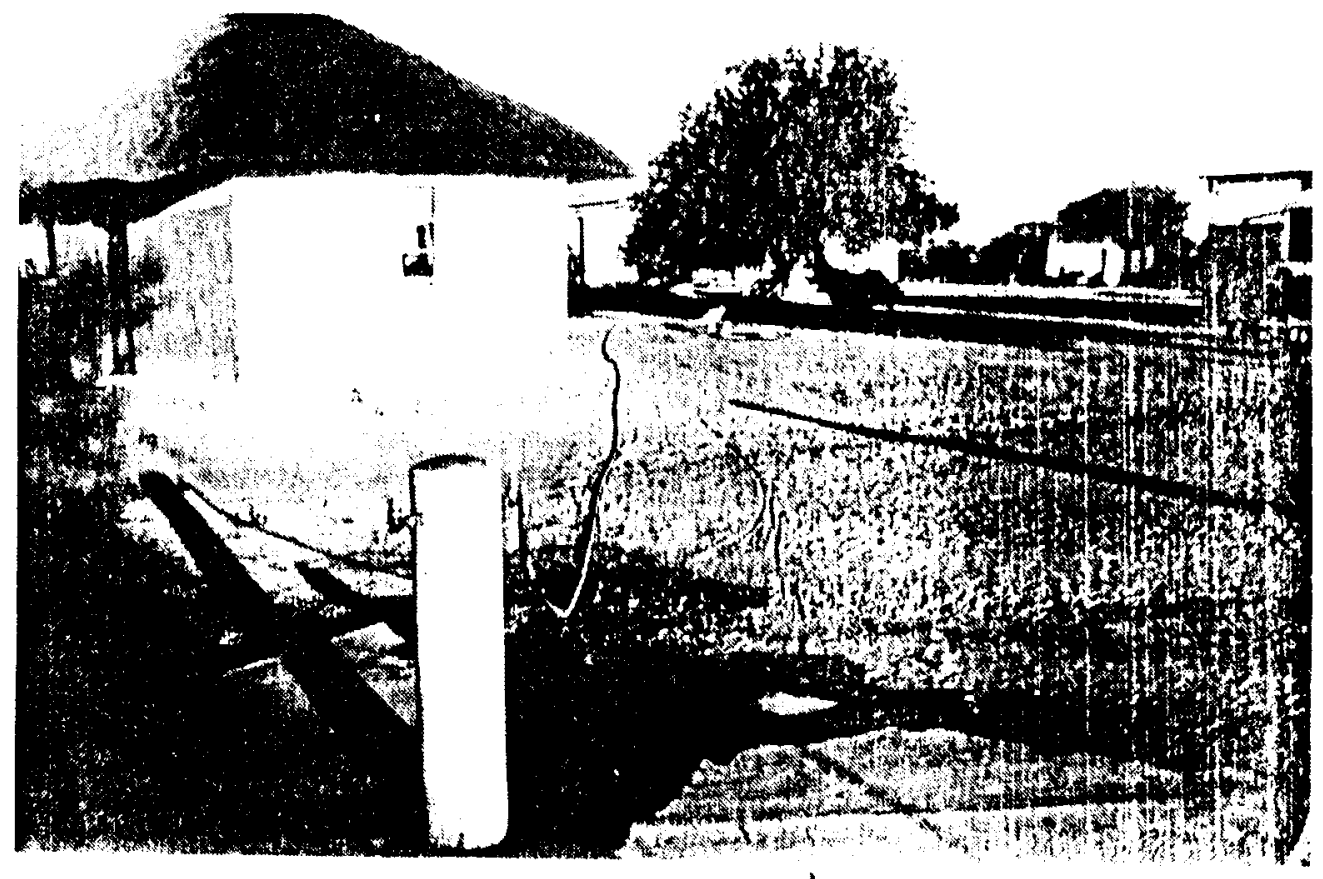

Fig 2.19 The village wntertnp

\subsection{Dripwater irrigation}

This manual does not go into how to connect the concrete benches to a drip water irrigation system. If dripwater irrigation is considered, there is information available

$\Lambda$ dripwater irrigation system is costly. For a smaller cultivation scheme ( $1-20$ benches) where manpower for hand-watering is easily available, a dripwater system might be an umnecessary expense.

Once the dripwater system is installed, it is easily taken care of. It is important, though, to ensure that the holes where the water drips out into the soil are not clogged. The drip irrigation can give an even supply of water ( 2 liters/ hole and hour), well adjusted to the needs of the plants. There does not have to be any wastage of water 
For a smaller cultivation area ( $1-20$ benches), watering by hand with a hosepipe or a watering-can may be a cheaper solution than dripwater irrigation. The only cost is that of manpower. It is more difficult to control the water supply to the plants. There is no real risk of overwatering though. Thanks to the bowshaped botton the excess water leaves the benches by the drainage holes. It does not stay in the bottom of the benches to cause mould or root damage. It is enough to water the plants once every day in the summertime and once every two days in winter. One way of controlling the water supply is to water with a watering-can. A watering-can of 10 liters will be sufficient for a distance of about 3 meters along the benches on each watering occation, which means 7 watering-cans per bench. Note: if a hose pipe is used for watering there is a risk of splashing up sand out of the benches into the walking space in between. To avoid this, a sprinkler can be attached to the hose pipe or one's thumb can be put in the opening of the hose pipe to control the flow of water.

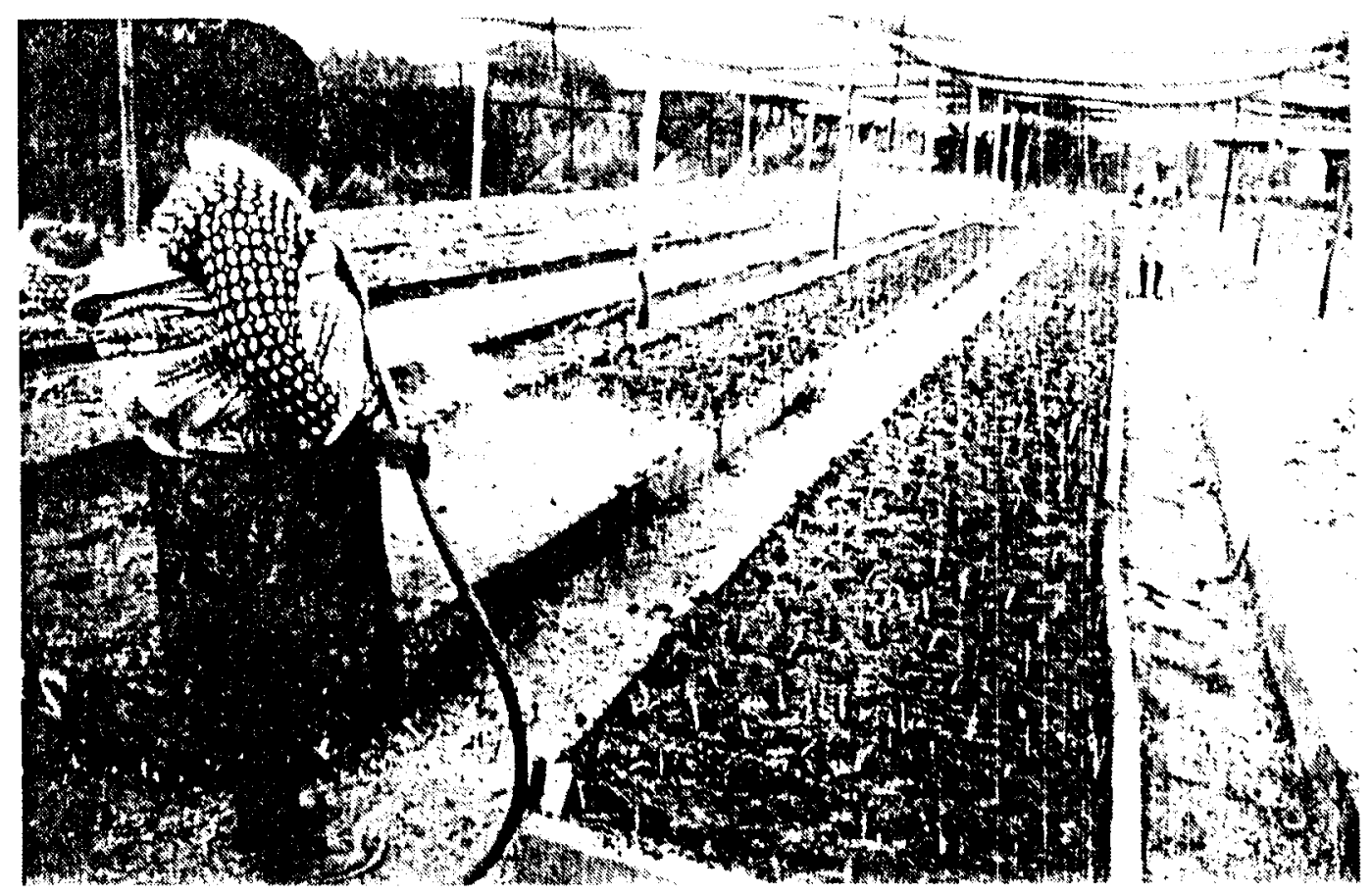

Fig.2.20 Watering the bench with a hose pipe 


\section{Pests and oulier problems}

Some common pests and other problems in vegetable gardens are listed below. Weeds

- Weeds are usually not a problem in sand. The few weeds are easily uprooted by hand.

- Mildew

- The leaves of the plant may become covered by a white powder, i.e mildew.

Nematodes

- Nematodes can affect the plants badly when only nematode-sensitive plants have been grown for several cultivation seasons and no rotation has been done, or when nematode infected sand has been transferred to a bench witls seedlings, for example.

Red spidemite

- The leaves curl up. Inside the leaves are the small, red spidermites.

Concrickers

- Corncrickets can eat through a vegetable garden destroying it in no time at all.
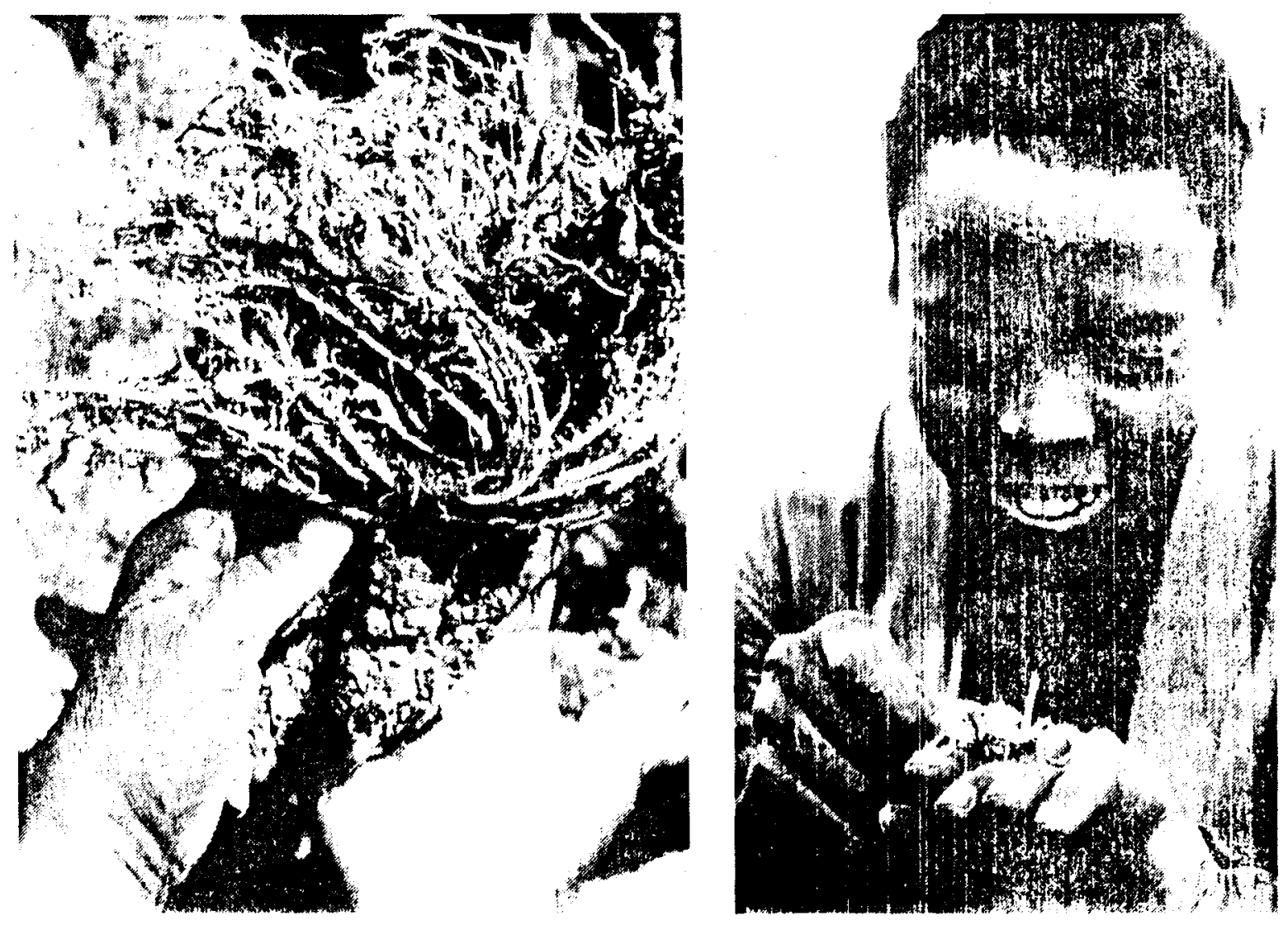

Fig. 2.21 Nematode infestation of the roots of a spinnch plant

- lig.2.22 Corn cricket

Plant lice, Thrips, White ants, Blister heetle are other examples of pests Iinst

- Frost affects frost-sensitive plants. Either the leaves or the whole plant are damaged. Hailstom

- The hailstones damage the leaves. The wind and hail break stems and branches of the plants. A severe hailstorm can badly damage the vegetable garden. 


\subsection{Pest control without pesticides; suggestions}

There are different kinds of biological substances that can be used as pesticides as a first measure of getting rid of different pests. There are also other easy and cheap measures to take. These methods are more or less liarmless both to man and to plants and soil. Examples of different pests are listed and suggestions on how to control them are given below.

\section{General suggestions:}

- Concentrate on growing vegetables that are resistant to different kinds of pests.

- Avoid watering early mornings and late evenings to prevent fungus growth.

- Keep good hygiene by removing old plants from the cultivation area.

- Practise rotation cultivation; not growing the same vegetables season after season in the same spot, to maintain a good balance in the soil and a low nematode population.

\section{Mildew}

- Give a light dusting of Flour of sulphur, or a spray of soap water

\section{Nemalodes}

- Rotation of vegetables in the bench prevents infestation by nematodes. After growing a nematode-sensitive vegetable such as spinach, always rotate with less sensitive vegetables such as onions, leek, coriander, or New Zealand spinach.

- One way of killing off nematodes effectively is by solar pasturizing: Heat up the sand to more than 55 degrees Celsius by covering the bench with black plastic during mid day. After one hour, the plastic is taken off and the sand in the bench is turned with a spade. This procedure is repeated until all the sand in the bench has been heated up.

- Always keep seedlings in new or pasturized sand. Pasturize the sand in the seedling bed by pouring very hot water on the sand surface, which kills off nematodes. When dry; turn the sand with a spade and pour more hot water on top until all sand is pasturized.

- Fast-growing cultures such as radish or fast-growing sallad can work like catch crops. They lielp to lower the nematode population. After growing the catch crop, llirnw it away while its roots have been affected by nematodes. The nematodes have now gone from the soil into the roots.

- Letting the nematode infested area lie fallow for 4 weeks or more, and then letting the sand dry out, can lower the total nematode population from $100 \%$ to $10 \%$.

- In the winter season, when the temperature sometimes drops below 10 degrees Celsius, the nematode population naturally stays at a low level as the nematodes do not multiply at a temperature below 10 degrees Celsius. In the summer season, with higher temperatures, often above 30 degrees Celsius, the nematodes can multiply rapidly

\section{Red spidemite}

- Give a light dusting with Flour of sulphur in the evening. An altemative is to spray with Sunlight soap water.

Com crickets or the like

- Remove by hand as they appear in the cultivation. 
- The affected plant can be sprayed with a can of soap water.

\section{Carch crops}

- To prevent infestation of the cash crop it is possible to grow plants, catch crops, with high susceptibility to insect infestation, either in between the vegetable plants or at the side of the cultivation area. The insects go to the plants they prefer and multiply there while the vegetable plant remains relatively unaffected. The catch crop can then either be pulled out or, if growing to the side, be sprayed with, for example, a nicotine preparation to kill off the pest. The sprayed catch crop is not advisable for human consumption

\section{$17 y$ strip}

- The insects fly to it and get trapped on the sticky surface.

\section{Repellants}

- If there is a problem with white ants or termites, for example, its ppssible to grow a repellent plant such as garlic to keep the ants or termites away. Thit repellent can be grown in between the other vegetables. Garlic is a slow growing plant, 5-6 months. When the other vegetable is pulled out, leave the garlic to continue growing until it is ready. Other repellents are tagetes, onion and marygold for example.

\section{Tirquping}

- Blister beetle, which infests cowpeas, are attracted by blue colour. If a blue bucket filled with water is placed next to the cowpeas it will attract the beatles and the beetles can be caught. Other insects can be trapped by, for example, a net.

\subsection{Pest control with pesticides}

There are many different pesticides on the market. The different agricultural institutions and dealers have information on both what pesticide to use and how to use it when there is a problem. This manual does not intend to go into the issue of pesticides except very briefly. What is important to understand though when working with pesticides is that many of them are poisonous not only to insects, fungus, etc. but also to man Many of them are hazardous both to inhale and to get on the skin and can cause serious injuries. It is therefore essential for the user to be well informed on the safety precautions necessary when handling a specific pesticide. It is often necessary to wear both a facemask and protective clothing when applying a pesticide on the plants. Some pesticides that are sprayed on to the plants may also affect areas nearby, especially when applying on a windy day. Therefore it is also important to see that areas nearby, are cleared from people and animals. Sprayed plants cannot be eaten until the quantity of poisonous substance in the pesticide has decreased to an acceptable level in the plant. The length of the risk period depends on the pesticide. 


\subsection{Frost and hailstorms}

linst

- If there is a risk for frost, sensitive plants can be covered with a fine net or plastic 'during the night. Dead plants have to be removed to keep good hygiene in the bench.

\section{Hailstoms}

- To prevent plants from getting damaged by hail, the cultivation area can be covered by a frame work covered by netting. Apart from protecting against hailstorms this net can also be seen as a watersaving and sun-protecting measure. A net with a shading capacity of $20 \%$ or $30 \%$ could be recommendable.

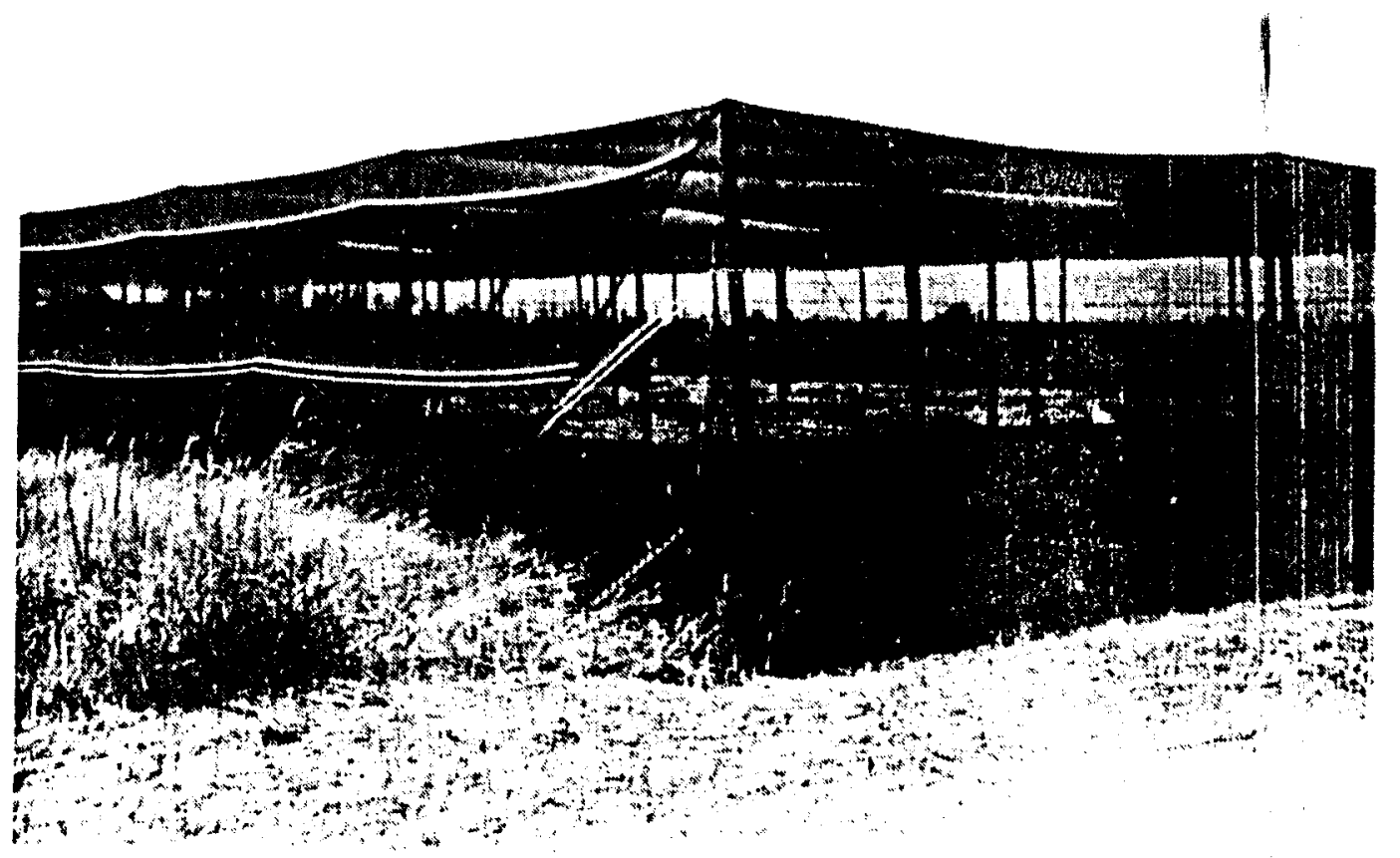

Fig. $2.23 \wedge$ protective construction of nelling covering a bench area 


\section{Ihe bowshaped concrete bench garden; an example}

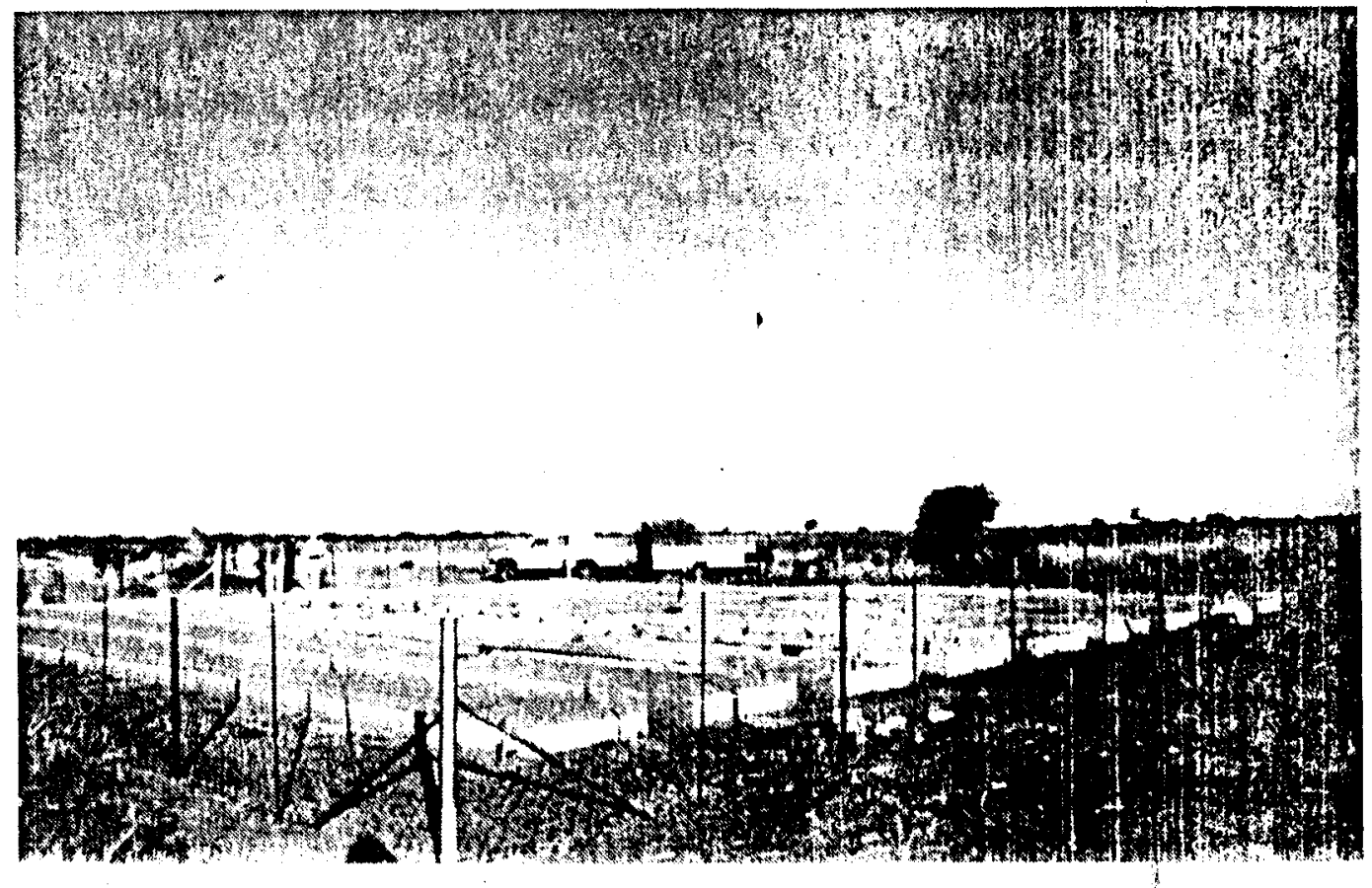

Fig. $2.24 \wedge$ vegetable plantation under construction in the village of (iakutwe

In the villages of Mmapane and Gakutwe, in the countryside aboill $20 \mathrm{~km}$ outside Gaborone, vegetable gardens with concrete benches have been set up by members of the villages. In each village there is one garden which consists of ten bowsliaped concrete benches, $1.20 \mathrm{~m} \times 20 \mathrm{~m}$, plus a shorter seedbed. $A$ framework of netting has been built around the garden to protect from excess sun and hailstorms. The whole garden is surrounded by a fence to keep animals out. The size of the garden is about 500 sq $\mathrm{m}$ (c: $: 20 \mathrm{~m} \mathrm{x}$ $25 \mathrm{~m}$ ). The benches are irrigated by hand with hose pipe once a day. In the village, there is a separate tap for the garden which enables correct payment for water usage.

The Baptist mission contributed with the initial capital to cover the construction of benches, netting and fence, about P 5000:- The people who were going to work in the garden contributed with their labour. The initial advice on construction and fertilizing etc. has mainly been given by a community developer from the Baptist mission while the village agricultural extension officer is assisting with further advicse.

The village development council chose three women in each village to work the benches. They run the garden as their own enterprise. They are working part time. It took only about eighteen months of production at the garden in Mmapane for the accumulated profit of vegetables sold to cover the initial costs. The garden in Gakutwe was not yet in production at the time this manual was written.

One of the main aims for starting up the gardens has been to raise the nutritional status in food for village members. Today, the produce from the garden well covers the village needs of vegetables. A part of the produce is also sold in Gaborone. 


\section{APPENDLX}

\section{How to mix concrete}

To get a strong and durable concrete it is important to mix the sand and cement carefully.

Suggested tools: spade, wheelbarrow

- Dump the sand ( 4 or 6 wheelbarrows, depending on the mixture being made, see next page) in a wide heap. Pour and spread the cement evenly over the heap.

- Shovel the mixture from the edges up on top of the heap.

- Shovel from the heap to make a new heap turning each shovel of mixture in the air on top of the new heap. Repeat the procedure of making a new heap twice more to get a good mixture.

- Make a wide hollow in the middle. Pour in the water.

- Turn first in the inner edges of mixture into the water. Then start turning in the outer edges into the water until a heap is made.

- Shovel from the heap to make a new heap 2-3 times to get the water mixed in properly.

- The concrete mixture is ready.

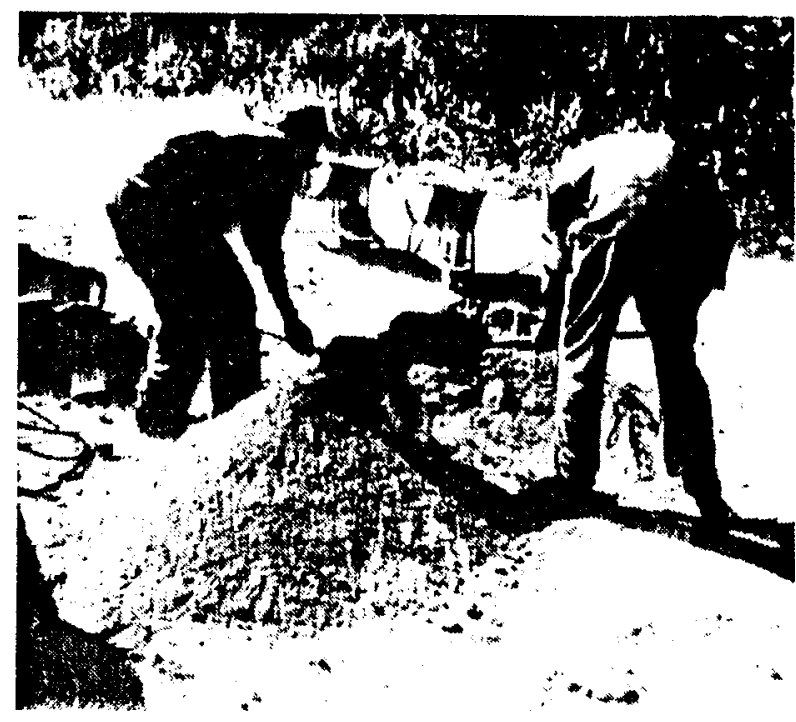

Fig.2.25 Mixing of the concrete

Fig.2.26 Adding water to the dry conerete mixture

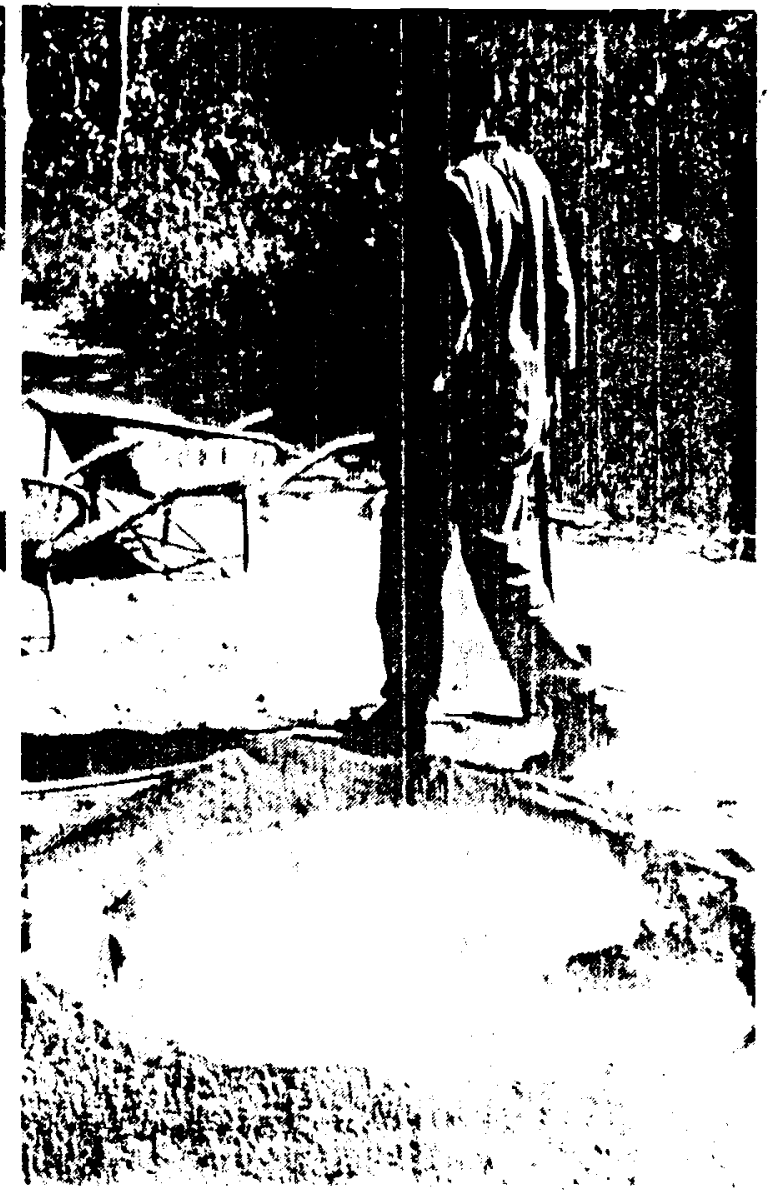




\section{Concrete mixes}

In the mixes for construction of the concrete bench coarse river sand is used. The reason for this is that the grains in that particular sand are more uneven than those of the Kalahari sand, for example, and thus make a more durable concrete.

Note; avoid making big mixes. There is a risk that the work cannot be finished the same day. The concrete easily dries up overnight.

- Slabs

4 wheelbarrows of coarse river sand

1 bag of cement

2 buckets of water makes ...13-14 concrete slabs

It takes about 3 mixes to make one concrete bench $(191 / 2+191 / 2+1+1=41$ slabs $)$. To be on the safe side; calculate for $31 / 2$ mixes in case the dividing of slabs (no. 19) does not work satisfactorily or the mix only makes 13 slabs.

\section{- Fumbis}

4 wheelbarrows of coarse river sand

1 bag of cement

water until soft porridge consistency

2 inixes are needed for one concrete bench. Left-over concrete can be used for the short sides and to fill in the gaps between slabs.

\section{- Concrete boltom}

6 wheelbarrows of coarse river sand

I bag of cement

water until soft porridge consistency

2 mixes are needed to cover the whole bottom of the bench with a $25 \mathrm{~mm}$ thick concrete layer.

- Skimming

$A$ good half of a wheelbarrow of anthill soil for example

$1 / 4$ bag of cement

water until loose gruel consistency

One mix should cover the whole concrete botton. 
Suggested tools: mould, broom, wheelbarrow, spade, plank (or similar)

Information on how to mix concrete; see appendix

Information on different concrete mixes; see appendix -Slabs

Note; make the slabs on a hard floor of earth or concrete. It is important to be able to keep the floor clear. The services of a local fitter and turner will be required to construct the mould for the slabs forming.

Measurements: Each slab is $1 \mathrm{~m}$ long, $23 \mathrm{~cm}$ high, $7.5 \mathrm{~cm}$ wide at the base and $3.5 \mathrm{~cm}$ wide at the top.
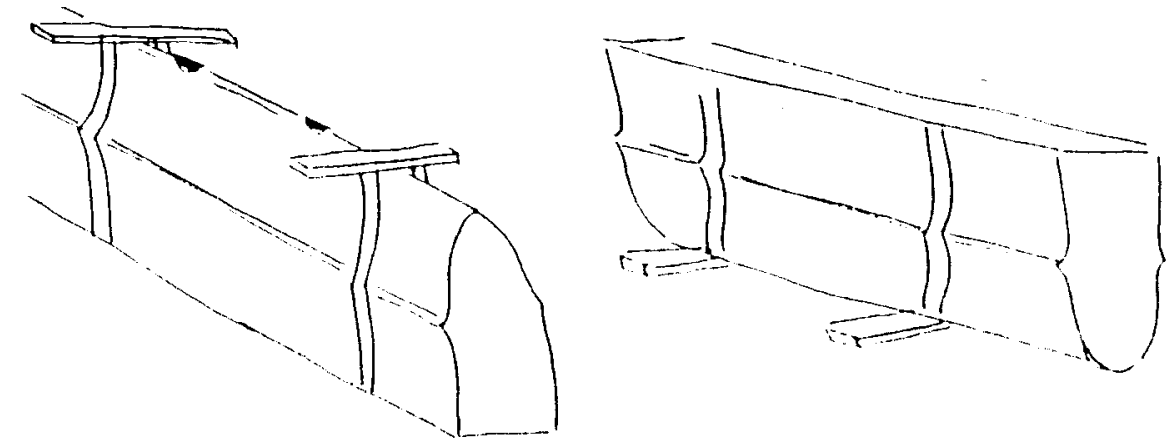

Fig. $2.27 \AA$ simple mould for the construction or slabs. Note the air holes on the bottom of the mould

- Mix the concrete for the slabs.

- Fill concrete into the mould until it is overfull. Pack the concrete well and scrape away excess concrete with the plank.

- Tum the nould slowly and carefully to the side.

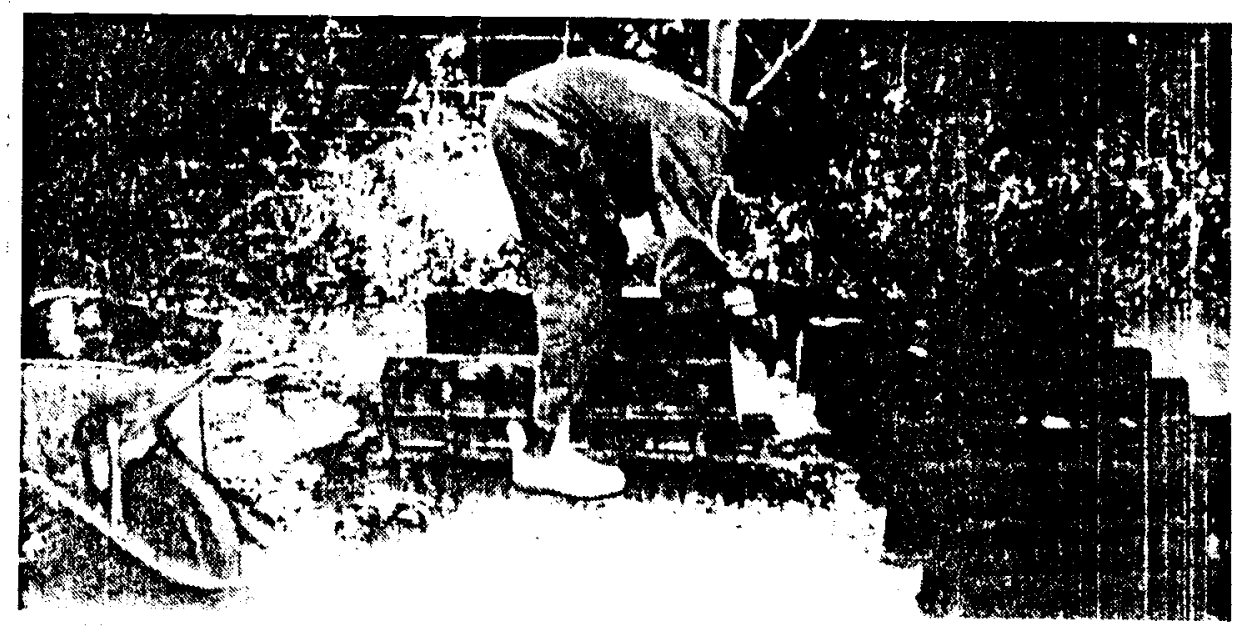

Fig 2.28 Filling the mould

- Sweep the floor in front of the mould.

- Turn the mould quickly and firmly upside down. Pull it carefully straight up. Note: the holes in the bottom of the mould are air holes. They make it easier for the moulded slab to come loose from the mould. 


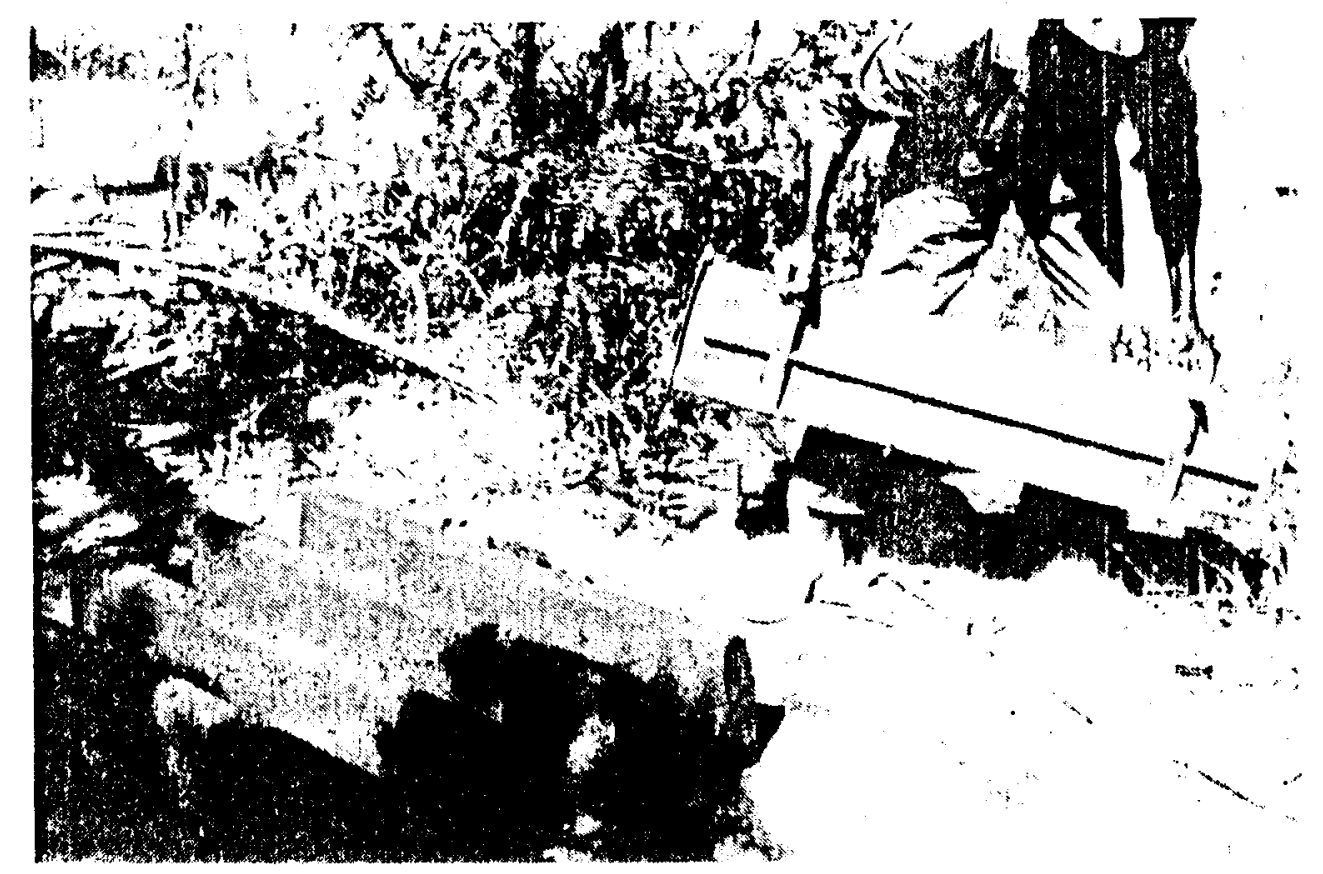

Fig.2.29 l.ifting the mould

- Sweep in front of the newly made slab to clear the space for the next slab.

- If a slab is not straiglit it is better to make it over again. It is important that the slabs are straight otherwise the bench will not be straight.

- When all slabs are made, let them dry for at least 3 days.

lig. 2.30 Slabs

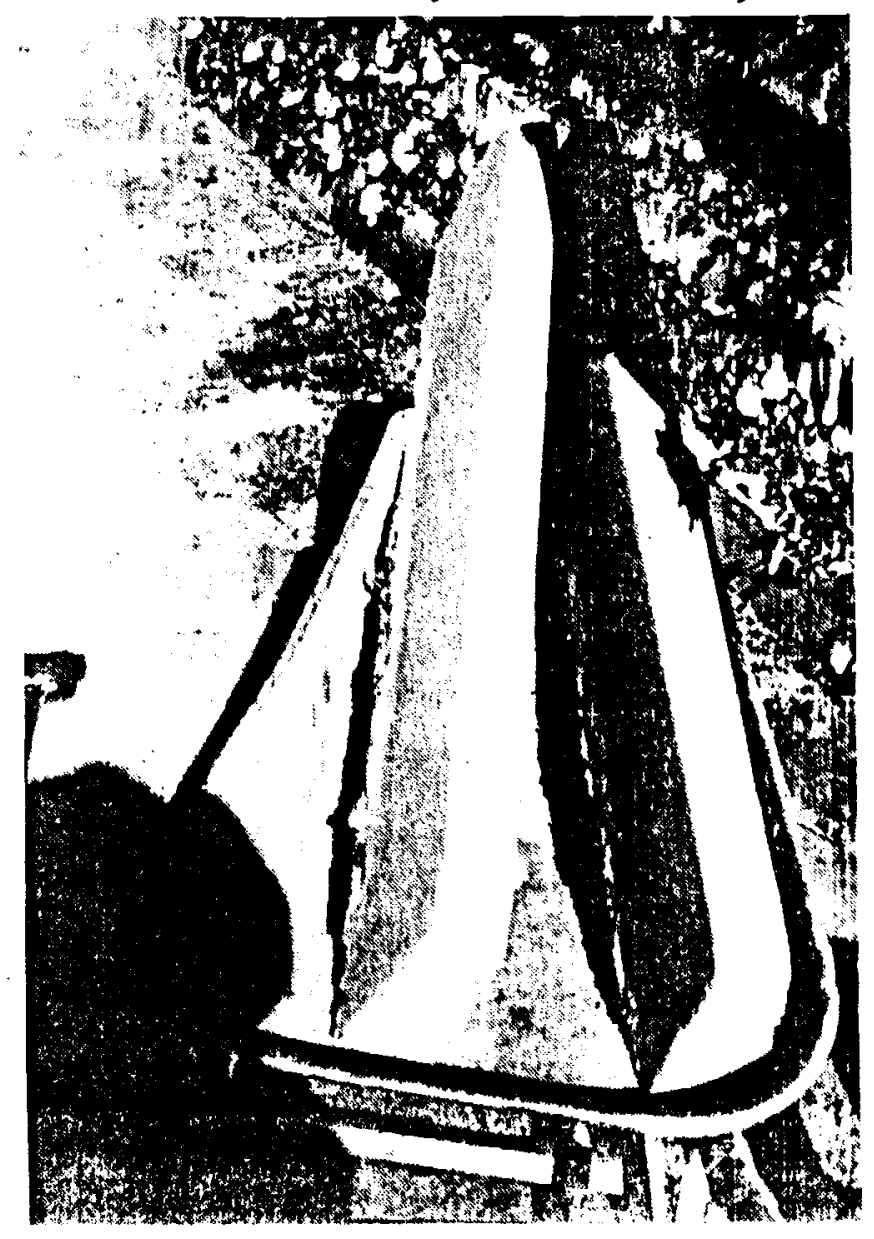


Sowing in scedtray

(if a proper nursery is available)

Suggested tools: Stamp, sieve

- Fill the plastic seed tray with compost.

- Water the soil and stamp with a small stamp.

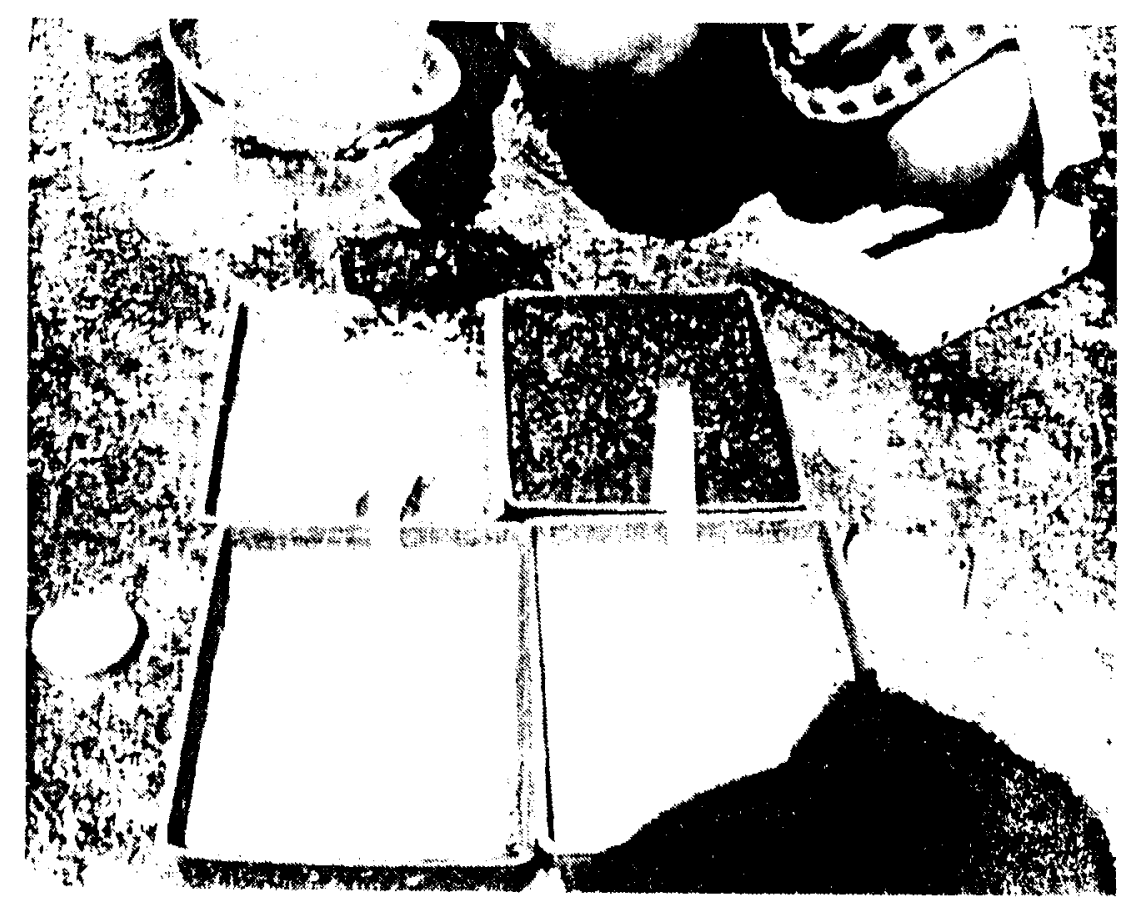

Fig.2.31 Sowing in seed tray. Note the small stamp

- Sprinkle a generous but thin layer of seeds on top.

- Cover the seeds with a thin layer of sand using a sieve

- Water the seed tray.

- Place the seed tray in a bench in the nursery.

- Put a name tag in the tray with date and name of vegetable.

- Water daily.

- When the seedlings are about $5 \mathrm{~cm}$ high they can be replanted into seedling trays. 


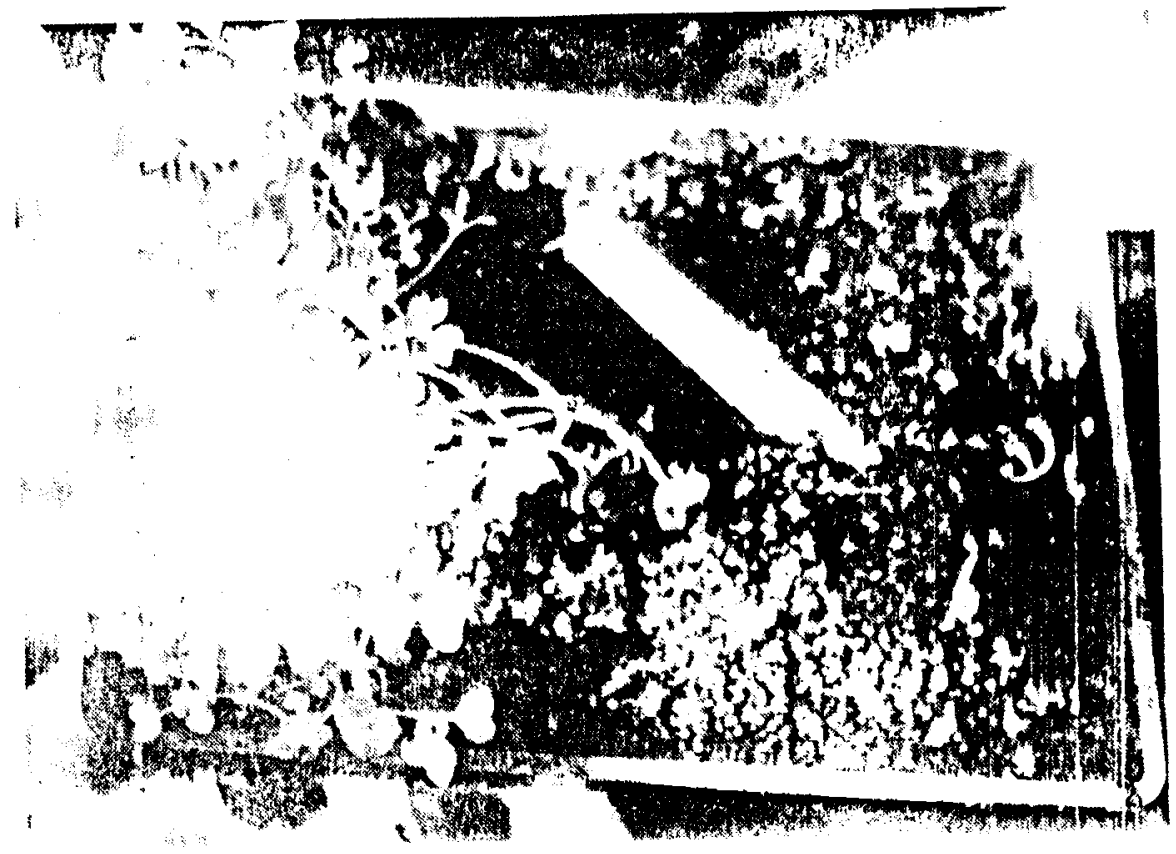

Fig.2.32 Chomolier sedlings ready to replant

Fig. 2.33 Replanting of seedlings into individual trays
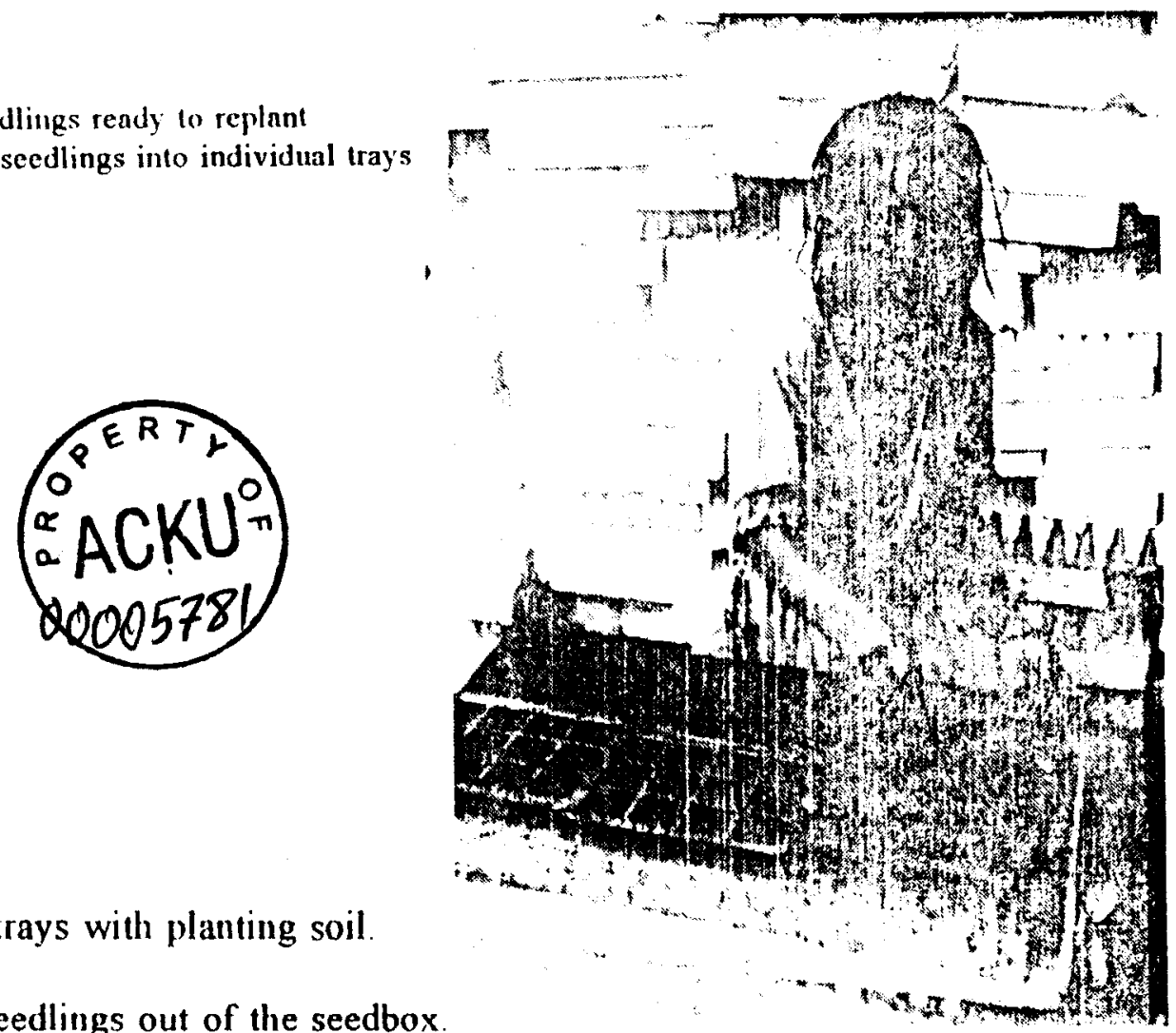

- Fill the seedling trays with planting soil.

- Water the trays.

- Lift a bunch of seedlings out of the seedbox.

- Make a hole for one seedling in each and every seedling box in the trays and plant the seedlings. The whole root and part of the stem should go down into the hole. Press the soil lightly around the seedling.

- Water the seedling trays and place them in the nursery. 